\title{
Biocatalytic self-assembly of tripeptide gels and
}

\section{emulsions}

Inês P. Moreira ${ }^{1}$, Tomasz K. Piskorz ${ }^{2}$, Jan H. van Esch ${ }^{2}$, Tell Tuttle ${ }^{1}$, Rein V. Ulijn ${ }^{1,3,4,5}$

${ }^{1}$ WestCHEM, Department of Pure and Applied Chemistry, University of Strathclyde, 295

Cathedral Street, Glasgow G1 1XL, UK

${ }^{2}$ Department of Chemical Engineering, Delft University of Technology, van der Maasweg, 2629 HZ Delft, The Netherlands

${ }^{3}$ Advanced Science Research Center (ASRC), City University of New York, 85 St Nicholas Terrace, New York NY10031, USA

${ }^{4}$ Department of Chemistry and Biochemistry, City University of New York - Hunter College, 695 Park Ave., New York, NY 10065, USA

${ }^{5} \mathrm{PhD}$ Programs in Chemistry and Biochemistry, The Graduate Center of the City University of New York, New York, NY 10016, USA

KEYWORDS. Emulsions, Self-assembly, Responsive, Peptides, Enzyme, Interface 
ABSTRACT. We report on the biocatalytic activation of an (unprotected) self-assembling tripeptide to stabilize oil-in-water emulsions on-demand. This is achieved by conversion of a phosphorylated precursor into a hydrogelator using alkaline phosphatase as the trigger. The rate of conversion, controlled by the amount of enzyme used, is shown to play a key role in dictating the morphology of the nanofibrous networks produced. When these amphiphilic tripeptides are used in biphasic mixtures, nanofibers are shown to self-assemble at the aqueous/organic interface but also throughout the surrounding buffer, thereby stabilizing the oil-in-water droplet dispersions. The use of enzymatic activation of tripeptide emulsions gives rise to enhanced control of the emulsification process since emulsions can be stabilized ondemand by simply adding alkaline phosphatase. In addition, control over the emulsion stabilization can be achieved by taking advantage of the kinetics of de-phosphorylation and consequent formation of different stabilizing nanofibrous networks at the interface and/or at the aqueous environment. This approach can be attractive for various cosmetics, food or biomedical applications since both tunability of tripeptide emulsion stability and on-demand stabilization of emulsions can be achieved. 


\section{INTRODUCTION}

Emulsifiers or surfactants are substances that create and/or stabilize emulsions by decreasing the interfacial tension between water and a water immiscible solvent (typically an oil). The creation of temporarily stabilized emulsions is crucial in a variety of industrial processes such as equipment cleaning, enhanced oil recovery, cosmetic emulsion formulations and biological applications, when emulsions or foams are desired only during a specific stage ${ }^{1-3}$ The ability to control the stabilization/destabilization of emulsions has been widely studied over the past years. Among the stimuli-responsive emulsifiers designed are those that respond upon changing $\mathrm{pH}{ }^{4-6}$ temperature, ${ }^{7}$ light irradiation ${ }^{8}$ or exchange of gases $\left(\mathrm{CO}_{2} / \mathrm{N}_{2}\right){ }^{1-2}$

Peptides are attractive building blocks for self-assembled stimuli-responsive materials ${ }^{9-11}$ (including emulsions) since they are chemically versatile, biocompatible and biodegradable, which is desirable for various medical, pharmaceutical, cosmetics, food or nanotechnological applications. Several peptide amphiphiles have been shown to self-assemble into different nanostructures through the hydrophobic effect, aromatic interactions and H-bonding, forming self-supporting gels. ${ }^{12-15}$ The responsiveness in these systems is achievable because these structures are assembled through weak non-covalent interactions that easily rearrange upon environmental or chemical changes.

In addition to environmental changes such as temperature and $\mathrm{pH}{ }^{16-17}$ (bio-) catalytic reactions have been extensively used to control self-assembly (or dis-assembly), allowing for a stimulus to be applied at constant, physiological conditions. The first example of the use of an alkaline phosphatase to trigger the formation of a hydrogel by the dephosphorylation of 9fluorenylmethoxycarbonyl (Fmoc)-tyrosine phosphate ${ }^{18-20}$ preceded several others. ${ }^{21-22}$ 
Hirst et al. have shown that the amount of biocatalyst used can direct the self-assembly pathway resulting in (kinetic) control of the supramolecular organization of the final supramolecular structure..$^{23}$ They also demonstrated that these kinetically locked gels may be 'unlocked' to access a minimum energy state by performing a heat/cool cycle. ${ }^{23}$ The kinetics of self-assembly and subsequent gelation control have been studied by varying different parameters, ${ }^{24}$ such as ionic strength of the peptide solution, ${ }^{25}$ peptide concentration ${ }^{26}$ or mutation of the peptide sequence. ${ }^{27}$ The balance between kinetic and thermodynamic aspects of peptide assembly and gelation are still far from fully understood and are difficult to precisely control, despite continued investigation..$^{28-29}$

We recently demonstrated the possibility of stabilizing emulsions on-demand, by making use of a biocatalytically-triggered self-assembly of nanofibrous networks of aromatic peptide amphiphiles (Fmoc-peptides) at the aqueous/organic interface. ${ }^{30}$ However, Fmoc-peptide amphiphiles contain a non-biological component, which may not be acceptable for specific applications (cosmetics, food, etc.). As a biocompatible alternative to Fmoc-peptides, it has been demonstrated that a number of tripeptides are suitable self-assembly motifs which show nanofibrous gelation. In particular, the tripeptides containing two adjacent aromatic amino acids flanked by an acidic or basic amino acid, such as lysine-tyrosine-phenylalanine (KYF) ${ }^{31}$ or by incorporation of both $\mathrm{L}$ and $\mathrm{D}$ enantiomers, as reported by Marchesan et al.. ${ }^{32}$ Interfacestabilizing peptides may act as either traditional surfactants which form a stabilizing monolayer at the interface (aspartic acid-diphenylalanine, DFF and FFD) or emulsifiers that self-assemble into interfacial nanofiber networks, stabilizing oil-in-water droplets (KYF, KFF and KYW (where $\mathrm{W}$ is tryptophan)). ${ }^{33}$ 
In this study, we combine the advantages of using unprotected tripeptides with the biocatalytic self-assembly of nanofibers in both aqueous and biphasic systems, creating the first reported example of biocatalytically assembled tripeptide gels and emulsions. This may be achieved by simply phosphorylating the tyrosine residues to reduce the self-assembly tendency in tripeptides, which is restored upon enzymatic dephosphorylation. The first objective is therefore (i) to demonstrate that an alkaline phosphatase can be used to dephosphorylate a non-gelator $\mathrm{H}$ Lys-Tyr $\left(\mathrm{PO}_{3} \mathrm{H}_{2}\right)-\mathrm{Phe}-\mathrm{OH}(\mathrm{KY} p \mathrm{~F})($ Figure $1 \mathrm{~A})$ and trigger the self-assembly into nanofibers in a bulk aqueous system. In addition, (ii) we interrogate the enzymatic pathway to assess whether varying the biocatalyst amount can kinetically control the fiber network (Figure 1B). The third aim is (iii) to investigate the entanglement of these nanofibers at the oil droplets' interface and/or within the aqueous environment to stabilize oil-in-water emulsions upon enzyme addition. Finally (iv), to investigate whether the emulsion stabilization and consequent properties of these emulsions can be tuned by varying enzyme concentration (Figure 1C - 2 and 3). 


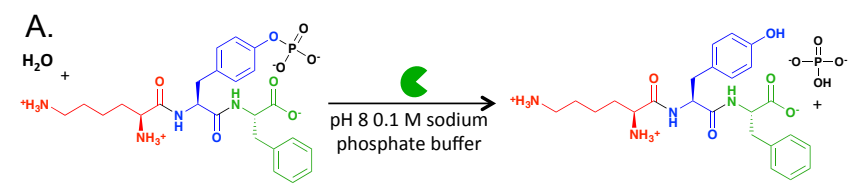

\section{B. Aqueous Buffer}

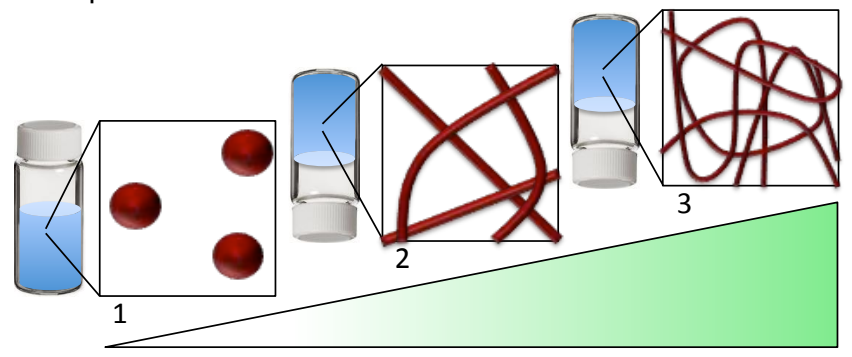

\section{Aqueous Buffer/Oil}

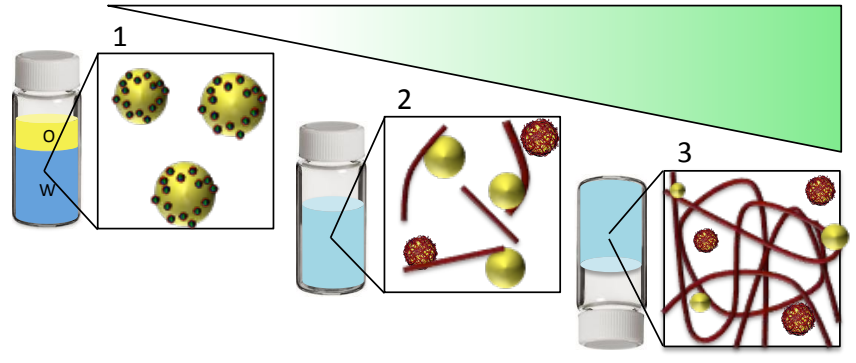

Figure 1. (A) Schematic representation of the enzymatic conversion from KYpF into KYF upon exposure to alkaline phosphatase (Green); (B) In aqueous buffer, alkaline phosphatase addition converts a precursor solution composed of KYpF spherical aggregates (B1) into a hydrogel composed of a KYF nanofibrous network, with the morphology and subsequent hydrogel stiffness controlled by the amount of catalyst which determines the kinetics of dephosphorylation (B2 versus B3); (C) In a biphasic system, alkaline phosphatase addition converts a two-phase system with some $\mathrm{KYpF}$ micelles at the interface of oil droplets $(\mathrm{C} 1)$ into a more established oil-in-water emulsion by the formation of nanofibers at the interface and surrounding oil droplets, with the emulsifying ability controlled by the specific amount of enzyme used (C2 versus $\mathrm{C} 3)$.

\section{RESULTS AND DISCUSSION}

\section{Biocatalytic conversion into hydrogelators}

The dephosphorylation from the precursor $\mathrm{KY} p \mathrm{~F}$ to the tripeptide $\mathrm{KYF}$ is followed by reversephase HPLC (Figure 2A). In order to study the biocatalytic self-assembly of tripeptides, samples with a final alkaline phosphatase (AP) concentration of $6.6,3.3,1.3$ and $0.07 \mu \mathrm{M}$ were prepared (which corresponds to 55.2, 27.6, 11.0 and $0.55 \mathrm{U} . \mathrm{mL}^{-1}$, respectively; See Preparation 
of Aqueous and Biphasic samples subsection of Materials and Methods). For the control sample, when no AP is added, $\mathrm{KYpF}$ remains unchanged after $24 \mathrm{~h}$, while tyrosine dephosphorylation is observed from the moment AP is added in the other samples (Figure 2A). As expected and previously shown by Bing Xu's group, ${ }^{34}$ a faster dephosphorylation occurs when more catalyst is present. The formation of reaction product follows a rate profile which is linear at the start, and then gradually decreases until full conversion is achieved. ${ }^{35}$ For all enzyme concentrations tested except $0.07 \mu \mathrm{M}$ AP, $>90 \%$ of KYF is formed after 24 hours, which is in line with the previously reported full dephosphorylation from Fmoc-Yp-OH into Fmoc-Y-OH within $24 \mathrm{~h}$, reported by Thornton and co-workers. ${ }^{36}$ The highlighted circles in Figure 2A represent the gelation time for each sample as determined by vial inversion.
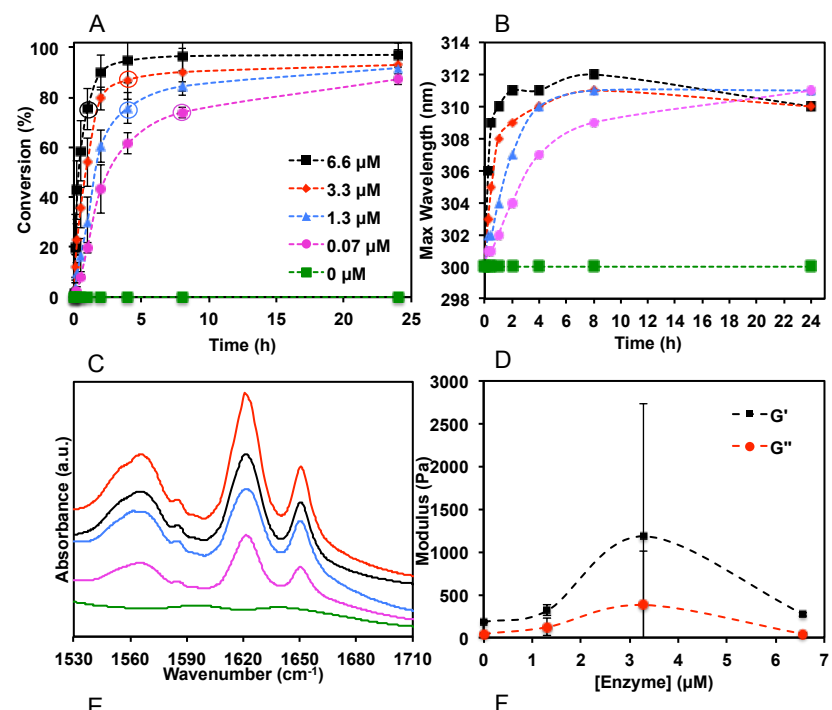

$\mathrm{E}$
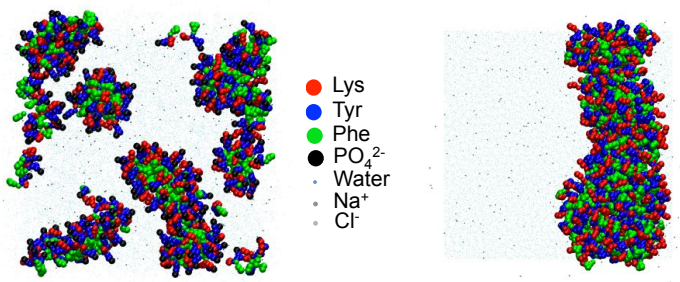

Figure 2. (A) HPLC conversion from KYpF into KYF in buffer when using different concentrations of alkaline phosphatase. Circles represent the first point where gelation was observed for each concentration as determined by 
vial inversion; (B) Maximum wavelength throughout the time from enzyme addition showing the red-shift occurring; (C) FTIR spectra for all samples when different AP amounts are used, measured $24 \mathrm{~h}$ after; (D) Rheology behaviour of the hydrogels produced when using different enzyme concentrations, measured at $24 \mathrm{~h}$ (average moduli between 0.1 and $10 \mathrm{~Hz}$ plotted); Snapshot after $10 \mu$ s CG-MD simulation of KYpF (E); and KYF $(\mathrm{F})$, using color labeling described in the inset.

In order to investigate the supramolecular structures formed, spectroscopic techniques were used to further characterize the non-covalent interactions involved in the self-assembly process for all samples where different enzyme amounts were used. From fluorescence spectroscopy, all the samples, including the precursor solution $\mathrm{KY} p \mathrm{~F}$, present a tyrosine emission peak at approximately $300 \mathrm{~nm}$. However, upon the addition of alkaline phosphatase, a gradual red-shift is observed, as seen in the time-course for the maximum wavelength of the different samples (Figure 2B). This shift indicates the formation of more favorable $\pi-\pi$ stacking interactions upon assembly and gelation, which occurs gradually after the AP is added. For each enzyme concentration, similar red-shifts are observed (to $311 \mathrm{~nm}$ ), but they appear at different rates (see Supporting Information, Figure S1D, for further details regarding the red-shift of each sample at different timings). As may be expected, higher enzyme concentrations show more rapid emergence of red-shifts over time, proving self-assembly occurs more rapidly for the $6.6 \mu \mathrm{M}$ AP sample and slower when $0.07 \mu \mathrm{M}$ of enzyme is used. The full spectra at $1 \mathrm{~h}, 2 \mathrm{~h}$ and $24 \mathrm{~h}$ (Supporting Information, Figure S1A, B and C), reveal a gradual intensity drop for the peak at around $300 \mathrm{~nm}$, which is due to the increase in opacity when a solution is transformed into a hydrogel. For the lowest enzyme concentration used in this study, a gel is formed between 4 and $8 \mathrm{~h}$, occurring later due to the slower dephosphorylation, which was already apparent from the HPLC time-course (See Supporting Information, Figure S2A for conversion in the first 60 min). Altogether, these observations provide evidence that the kinetics of the self-assembly process and hydrogel formation influence the nature of the nanostructures formed, which is 
further investigated by FTIR and microscopy techniques.

The amide I region of the spectra obtained by Fourier transform infrared (FTIR) was analysed to observe H-bonded networks between the amide backbones for the different samples (Figure 2C). The precursor $\mathrm{KY} p \mathrm{~F}$ (when no alkaline phosphatase is added) does not present evident peaks in this region, except a low intensity broad peak at around $1590 \mathrm{~cm}^{-1}$, characteristic of the deprotonated fraction of C-terminus carboxyl groups. ${ }^{37}$ However, the appearance of intense peaks at the amide region proves that $\mathrm{H}$-bonded networks are formed during biocatalytic assembly. The analysis of FTIR peaks for tripeptide assemblies cannot be simply extrapolated from the secondary structure of proteins. ${ }^{37}$ However, the peaks around 1620 and $1650 \mathrm{~cm}^{-1}$ indicate the formation of organized hydrogen bond networks between the amide groups of the tripeptides. The shift from the carboxylate peak to approximately $1560 \mathrm{~cm}^{-1}$ in the amide II region for the hydrogels formed upon addition of enzyme is related to the $\mathrm{NH}_{2}$ bending vibration. This change is explained by the formation of salt bridges between the C-terminus and the N-terminus of the peptide chain or that terminal carboxyl group and lysine's side chain. This is consistent with the interpretation reported previously for non-enzymatically assembled $\mathrm{KYF}^{31,33}$ It is notable that a more well-ordered H-bonded structure is formed when the KYF is biocatalytically produced (for comparison, see Supporting Information, Figure S3). Since 87\% KYF had already been produced and a gel was formed by the time that the FTIR was performed (24 h), the broader peaks observed for the lower enzyme concentration $(0.07 \mu \mathrm{M})$ confirm that a slower conversion gives rise to less well-ordered H-bonded network. The formation of more ordered structures have been reported before when increasing the enzyme amount. ${ }^{23}$ It should be noted that sharper peaks are observed for the $3.3 \mu \mathrm{M}$ hydrogel, and these are broader again at higher enzyme concentration (See Supporting Information, Figure S4A for trend), which 
suggests that there is an optimum enzyme concentration (ca.3.3 $\mu \mathrm{M}$ AP) for the formation of more well-ordered H-bonded networks. We propose that at higher enzyme concentration the formation of KYF peptides outpaces the kinetics of the self-assembly process, giving rise to less ordered assemblies.

In order to further assess the differences in supramolecular interactions between KYF and $\mathrm{KY} p \mathrm{~F}$, that is unable to form fibers, computer simulations were used. Coarse-grained molecular dynamics simulations of $\mathrm{KYpF}$ (Figure 2E) and KYF (Figure 2F) in a water box showed different assembly tendencies after being run for $10 \mu \mathrm{s}$. KYpF assembles into aggregates, while KYF forms more ordered nanofibers, as already reported. ${ }^{33}$ This result is consistent with observed experimental behavior. However, surprisingly, the modelling results indicate that the lack of fiber formation in the case of $\mathrm{KYpF}$ is not due to increased repulsion between the phosphate anions, as initially expected from related systems with phosphorylated tyrosine..$^{18,30}$ Rather, through the parameterization of the phosphate group (see Supporting Information, Figure S5, Figure S6, Figure S7, Table S1, Figure S8, Figure S9 and Table S2 for further details) it is evident that the lack of fiber formation in the case of $\mathrm{KYpF}$ is due to the greater hydration of the phosphate group in the modified tripeptide. The fact that the subtle change in the hydrophilicity of the modified tripeptide is the critical factor in determining the selfassembly ability of the compound, rather than specific interactions in the self-assembled state has important implications for the future development of related systems. As coarse-grained molecular dynamics simulations use a non-reactive force field, it is currently not possible to model the enzymatic conversion or the effect of enzyme amount on the reaction.

The morphology of the gels formed by biocatalytic gelation was studied using TEM. This imaging was performed $24 \mathrm{~h}$ after the addition of alkaline phosphatase, when all samples were 
hydrogels (except the no enzyme control). The precursor $\mathrm{KY} p \mathrm{~F}$ gives rise to a clear solution with only some aggregates observed (Figure 3A). Upon enzymatic cleavage of the solubilizing phosphate group, the amphiphilicity of the molecules is changed and self-assembly occurs creating nanofibrous networks. The morphology of the nanofibers observed by TEM after $24 \mathrm{~h}$ differs markedly when varying the enzyme concentration (Figure 3B-E and also Figure S10 from Supporting Information). The sample where low catalyst concentration $(0.07 \mu \mathrm{M})$ was used presents fibers of approximately $14 \mathrm{~nm}$ diameter (Figure 3F), while the sample where the highest amount was used $(6.6 \mu \mathrm{M})$ forms much thinner fibers (approximately $3 \mathrm{~nm}$ diameter). The latter presents a dense and entangled nanofibrous network, in contrast to the less entangled fiber bundles observed for the other hydrogels. The differences in fiber size and network type observed suggest that the growth pathways, gelator formation rate and gelation time (governed by the catalyst amount) can influence the final materials' structure. ${ }^{22}$ It is worth noting that when KYF gel is formed non-enzymatically by direct dissolution into a pH $80.1 \mathrm{M}$ phosphate buffer, the nanofibers formed are thicker than when using $6.6 \mu \mathrm{M}$ AP $(4.6 \pm 2.1 \mathrm{~nm})$ and less entangled (See Supporting Information, Figure S10F). This difference might be explained by the disordered nucleation and less organized gelation in comparison to the spatio-temporal controlled enzymatic dephosphorylation that leads to more uniform fiber formation. 

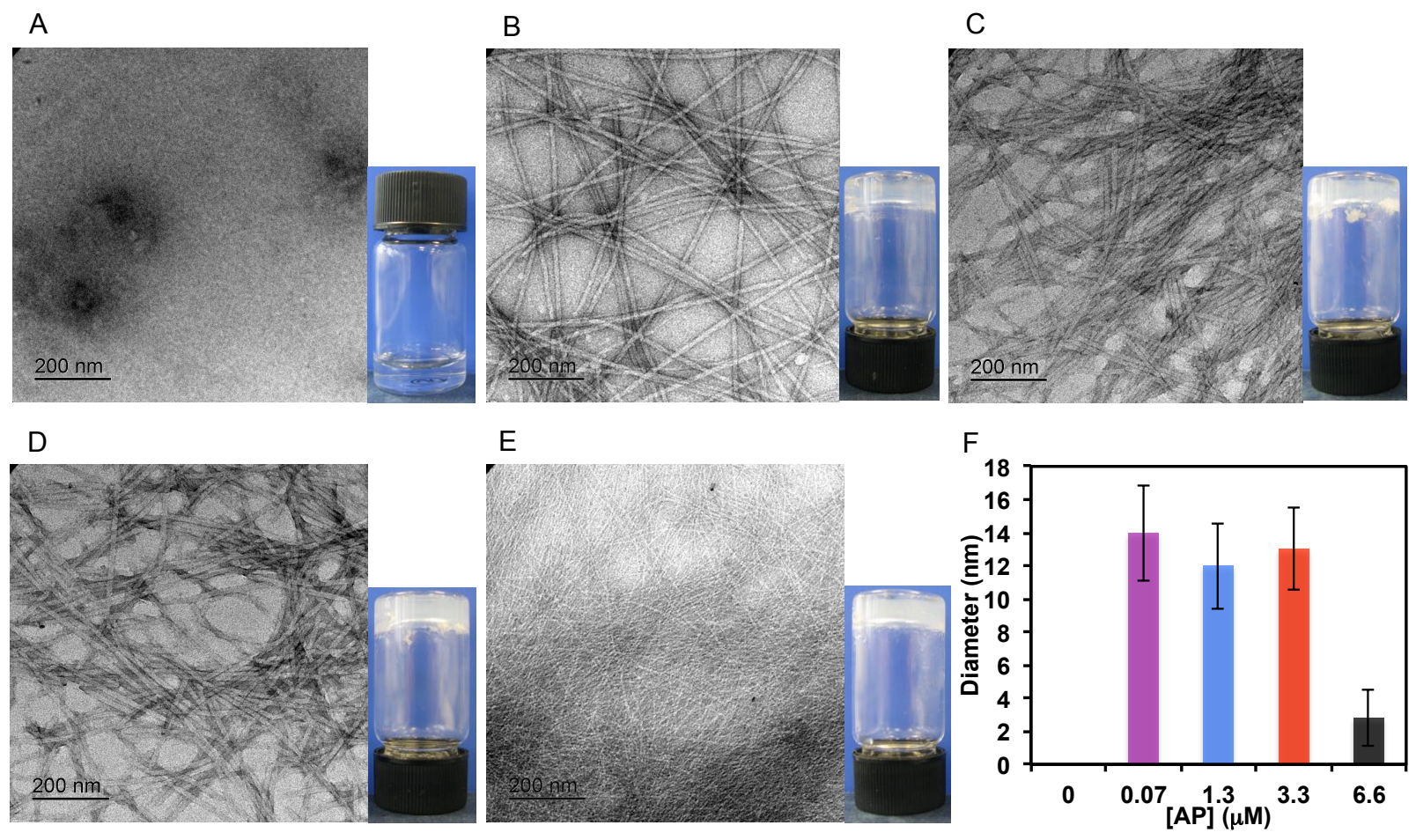

Figure 3. TEM images and macroscopic photographs (insets) taken $24 \mathrm{~h}$ after preparation of the aqueous samples: (A) KYpF precursor; (B) $\mathrm{KYpF}$ added $0.07 \mu \mathrm{M}$ alkaline phosphatase; (C) $1.3 \mu \mathrm{M}$ AP; (D) $3.3 \mu \mathrm{M} \mathrm{AP}$; (E) $6.6 \mu \mathrm{M}$ AP (more TEM images are presented in Figure S10); (F) Nanofiber diameter analysis for each concentration, showing much thinner fibers for the highest enzyme concentration tested.

In order to evaluate and compare the mechanical properties of the gel-type samples when using different enzyme concentrations, dynamic frequency sweep measurements were carried out (see Supporting Information, Figure S11 for all plots), after first performing the strain sweeps to ensure the correct range and conditions were used (Figure S13). In Figure 2D, the average storage (G') and loss (G') moduli from $0.1-10 \mathrm{~Hz}$ are plotted versus enzyme concentration (see Figure S12 for the average moduli between 0.1 and $100 \mathrm{~Hz}$ ). Based on the definition of Yan and Pochan, ${ }^{38}$ all samples except that obtained at $1.3 \mu \mathrm{M}$ AP present viscoelastic behavior as G' is more than one order of magnitude greater than G" (see Supporting Information, Table S3). This is in agreement with the macroscopic observation by vial inversion (Figure 3). However, there is an upturn in G' and G" moduli at higher frequencies (Figure S11), which is possibly 
explained by a thickening instability, as previously mentioned ${ }^{39-40}$ The highest elasticity would be expected for the sample with the highest level of entanglement of fibers (Figure 3E), as observed for an enzyme-triggered self-assembly of octapeptides. ${ }^{41}$ Even though the error bars for the $3.3 \mu \mathrm{M}$ alkaline phosphatase sample are larger than for the other enzyme concentration used, which suggests higher variability in the properties of this material, it presents the highest G' and G" values, decreasing again for the $6.6 \mu \mathrm{M}$ AP sample. This correlates with the sharper FTIR peaks observed for this sample (Figure 2C) and thus corroborates that there is an optimum enzyme concentration that gives rise to a stiffer sample. Boekhoven and co-workers have also reported a maximum storage modulus obtained for a certain concentration of catalyst aniline, with higher concentrations leading to the decrease of this $\mathrm{G}^{\prime}$ value. ${ }^{22}$ We propose that the presence of alkaline phosphatase in excess can be detrimental for the nanofibrous network and hydrogel production due to the fast dephosphorylation which outpaces the self-assembly rates, giving rise to formation of kinetically trapped disorganized regions. The effect is related to the kinetics of the self-assembly process, and not just enzyme concentration as the presence of the enzyme was shown not to be disruptive to the H-bonded networks when present together with the non-enzymatically produced KYF hydrogel (Figure S3, Supporting Information). Thus, as previously shown for esterase catalyzed assembly of a range of Fmoc-dipeptides, ${ }^{23}$ different metastable states of the same self-assembling tripeptide can be produced by simply varying the catalyst amount, which affects the conversion rate, non-covalent interactions, network morphologies and subsequent mechanical properties.

\section{Biocatalytic control over emulsion stabilization}


The system was also investigated in aqueous/organic biphasic systems in order to assess the capability of kinetically controlled fibrous networks to stabilize emulsions in different extents depending on the catalyst amount in use. When rapeseed oil is added to the $\mathrm{KY} p \mathrm{~F}$ in aqueous buffer (1:9 v/v) and homogenized using a top-bench homogenizer (See Preparation subsection of Materials and Methods), a temporary and unstable emulsion is formed, which separates into two phases in less than 1 hour. However, when alkaline phosphatase is added immediately after the oil addition and the mixture is homogenized for 10 seconds, a stable emulsion is created which remains for more than 1 week (Figure S20E). It is shown, using HPLC, that KYpF is transformed into KYF when AP is added to the biphasic mixture (Figure 4A). This shows that the enzyme is still active when adding rapeseed oil to the aqueous system, which was also proven by an enzymatic assay where the alkaline phosphatase is shown to retain its activity in a 9:1 buffer:rapeseed oil mixture, comparable to when in an aqueous buffer medium (See Supporting Information, Figure S14).

Following the finding that enzyme concentration dictates the conversion rate and subsequent formation of the nanofibrous entangled networks in the aqueous system, different alkaline phosphatase amounts were also used for the biphasic mixtures. From reverse-phase HPLC (Figure 4A), the conversion from $\mathrm{KY} p \mathrm{~F}$ into $\mathrm{KYF}$ was observed to be slower when less phosphatase is used, which is in agreement with what has been observed for the aqueous systems. 

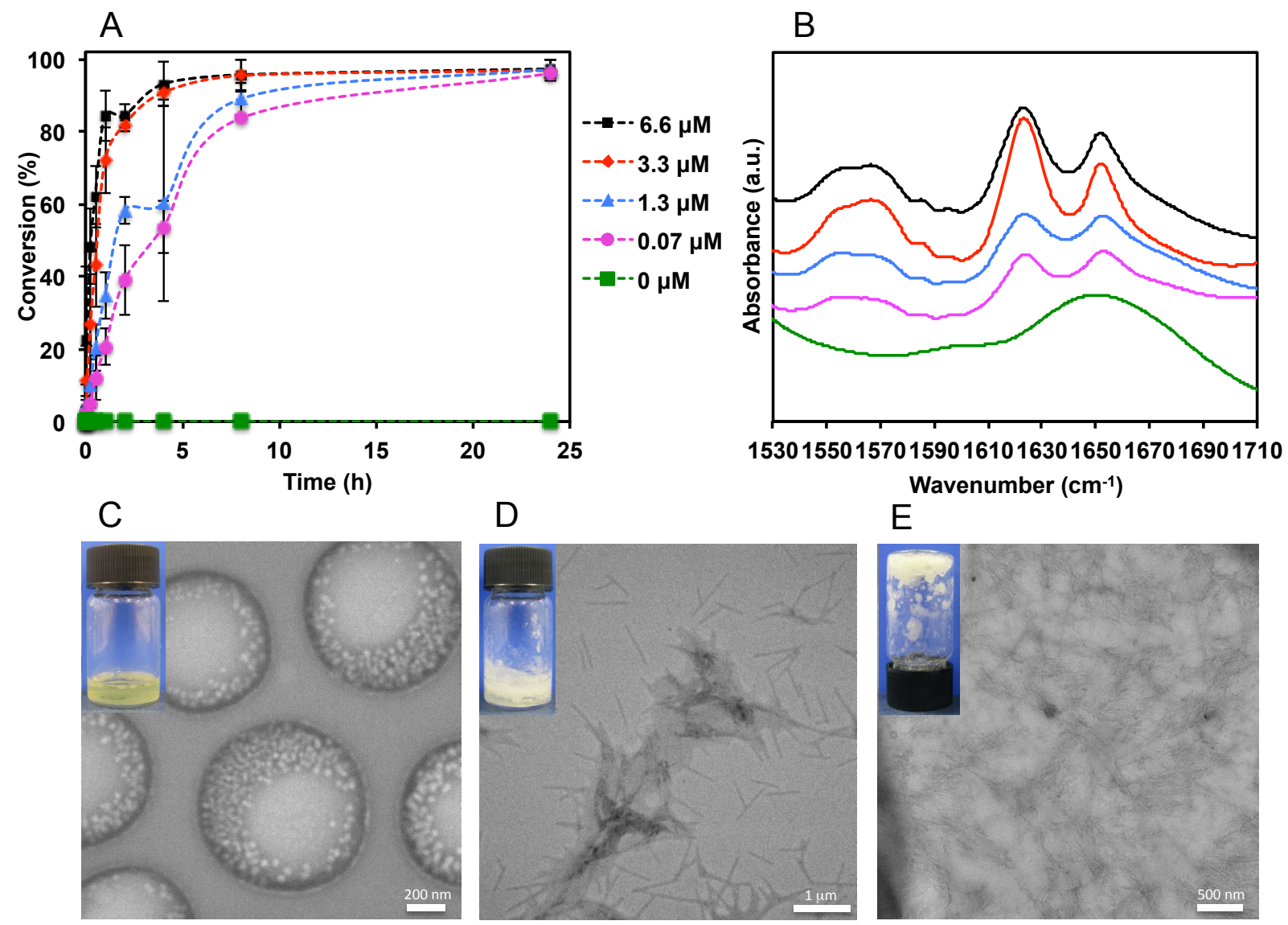

Figure 4. (A) HPLC conversion from KYpF into KYF in the biphasic system when enzyme is used at different concentrations; (B) FTIR spectra of the different enzyme concentration samples; Photographs of macroscopic aspect and TEM images obtained after 24 hours of the different 9:1 buffer:rapeseed oil samples: (C) KYpF control showing micelles at the interface of the oil droplets; (D) KYpF added $0.07 \mathrm{mM}$ alkaline phosphatase; (E) $6.6 \mathrm{mM}$ AP (more TEM images, including the ones for 1.3 and $3.3 \mathrm{mM}$ AP samples are presented in Figure S16).

To investigate the formation of self-assembled structures in the biphasic mixtures, FTIR spectroscopy was performed on the different samples (Figure 4B) after $24 \mathrm{~h}$ of preparation. Since the spectra are similar to those of the aqueous samples (Figure 2C), we conclude that the formation of self-assembled nanofibrous networks through the same key interactions occurs. This similarity in the FTIR spectra between aqueous and non-aqueous systems has been shown previously for an Fmoc-dipeptide system..$^{30}$ The $\mathrm{KY} p \mathrm{~F}$ biphasic system (no AP added) is not able to stabilize emulsions, which is shown by its de-emulsified appearance $24 \mathrm{~h}$ after 
preparation (inset of Figure 4C). Comparing the FTIR spectrum for $\mathrm{KY} p \mathrm{~F}$ in aqueous solution (Figure $2 \mathrm{C}$ - green curve) and in biphasic mixture (Figure 4B - green curve) reveals the appearance of a peak at around $1650 \mathrm{~cm}^{-1}$ for the biphasic state. This could possibly be associated with a parallel arrangement of the phosphorylated tripeptides forming micelles, Moreover, the presence of many small aggregates at the interfaces of the rapeseed oil droplets observed in the TEM image (Figure 4C) suggests the assembly of these micelles at the interface, differently than previously proposed for FFD and DFF. ${ }^{33}$ The peak at $1650 \mathrm{~cm}^{-1}$ can also be associated with the presence of rapeseed oil, which contains a carboxylic acid (see curve for the rapeseed oil only in Supporting Information, Figure S15). This could also explain the more similar relative intensity of the $1650 \mathrm{~cm}^{-1}$ and $1620 \mathrm{~cm}^{-1}$ peaks, in comparison to the aqueous samples (Figure 2C). When alkaline phosphatase is added, nanofibers are formed (Figure 4E), which are able to stabilize the rapeseed oil-in-water droplets and form more stable emulsions. Comparison of the spectra for the different emulsions reveals broader peaks for the samples where lower concentration of catalyst is added (and slower conversions occur), indicating less well-ordered H-bonded networks. Once again, there is an exception for the 3.3 $\mu \mathrm{M}$ AP sample, which presents sharper peaks than the highest enzyme concentration (See detailed trend in Supporting Information, Figure S4B), in agreement with the previous results from FTIR (Figure 2C) and rheology (Figure 2D) of the samples.

From the TEM images and macroscopic photographs taken after $24 \mathrm{~h}$ from enzyme addition and emulsion formation (Figure 4C-E and Figure S16 from Supporting Information), a significant difference is observable when varying the amount of catalyst used. All emulsions have the appearance of gel-like samples, except the $\mathrm{KY} p \mathrm{~F}+0.07 \mu \mathrm{M}$ AP sample and the no enzyme control. However, they are not considered to be self-supporting gels because they flow 
when the vial is inverted. While the emulsions with the lowest enzyme concentration are stabilized by the formation of some un-entangled short fibers in the environment of the droplets, the $6.6 \mu \mathrm{M}$ AP concentration emulsion is constituted by an entangled network of nanofibers that is able to stabilize small oil-in-water droplets. In addition to the droplet stabilization by interfacial nanofibrous networks as previously reported, ${ }^{30,42}$ another mechanism by which emulsions are stabilized is by the viscosity increase of the dispersed phase. Gelled emulsions or high internal phase emulsions (HIPEs) have been shown to delay or prevent coalescence or creaming through the gelation of the aqueous phase and consequent formation of a gel matrix where droplets are embedded..$^{43-45}$ This, together with the FTIR spectra, suggests the emulsion stability increases when increasing the enzyme concentration added to the aqueous/organic mixture. Fluorescence microscopy images were used to characterize the droplet size of the emulsions obtained when phosphatase was added in different concentrations, measured by image analysis and presented as histograms (see Supporting Information, Figure S17 and Figure S18). A smaller average droplet diameter is noted when more catalyst is used (Table 1), which corroborates the theory of higher emulsion stabilization when higher enzyme concentration is used and more entangled nanofibers are formed. In addition, the emulsions were also characterized after 1 week of storage at room temperature to study their relative stabilities (see Supporting Information, Figure S19 and Figure S20). The droplet size average increases for all samples after 1 week (Table 1), although it is observed that coalescence is retarded when nanofibrous networks are formed, which occurs predominantly for the highest enzyme amount used (Figure S20D).

Table 1. Droplet diameters observed for the different samples when using varying enzyme concentrations $24 \mathrm{~h}$ after preparation and 1 week after preparation 


\begin{tabular}{|c|c|c|}
\hline \multirow[t]{2}{*}[\mathbf{AP}]{$(\mu \mathbf{M})$} & \multicolumn{2}{|c|}{ Droplet diameter $(\mu \mathrm{m})$} \\
\hline & $24 \mathrm{~h}$ & 1 week \\
\hline 0.07 & $2.3 \pm 2.0$ & $3.9 \pm 3.6$ \\
\hline 1.3 & $2.1 \pm 1.5$ & $2.3 \pm 1.9$ \\
\hline 3.3 & $1.4 \pm 0.8$ & $2.2 \pm 2.1$ \\
\hline 6.6 & $0.9 \pm 0.6$ & $2.1 \pm 1.7$ \\
\hline 0 & No fluorescence & $+6.6 \mu \mathrm{M}$ AP: $1.6 \pm 1.3$ \\
\hline
\end{tabular}

Having demonstrated that the kinetics of assembly can influence emulsion stabilization in a tunable manner, we then investigate if enzymatic conversion provides temporal control - in that the emulsion can be formed when required. The activation of the emulsifying ability by adding an enzyme at different time points was shown previously for an Fmoc-capped dipeptide at a 1:1 water:chloroform system. ${ }^{30}$ In the current system, when alkaline phosphatase is added upon preparation of the emulsion and right before emulsifying it, the emulsion is still stable after 1 week, as already mentioned. In turn, when alkaline phosphatase is added to the 1-week old totally de-emulsified $\mathrm{KY} p$ F biphasic mixture (using a $6.6 \mu \mathrm{M}$ AP) and homogenized again, this is dephosphorylated into KYF at the same conversion rate, as demonstrated by HPLC (Figure 5A) and a similar gel-like milky emulsion is produced (Figure 5B). From FTIR spectra (Figure 5C), the peaks in the amide I region for the $\mathrm{KY} p \mathrm{~F}$ biphasic system when adding alkaline phosphatase after one week of storage are the same as the ones for the sample where the enzyme is added upon preparation. These results corroborate the presence of nanofibrous networks, formed through $\mathrm{H}$-bonded structures, even when the biocatalytic self-assembly and emulsion stabilization is triggered after one week of storage. 
The on-demand formation of nanofibrous-stabilizing emulsions is also shown by the fluorescence microscopy (Figure 5D) and TEM images (Figure 5E). The presence of fluorescent probe Thioflavin $\mathrm{T}$ (used to label the tripeptide aqueous solution before the oil addition) is mainly evident at the oil/water interface and less at the aqueous phase (Figure S19E), which suggests there are nanofibrous networks stabilizing the oil-in-water droplets as we reported previously. ${ }^{30,} 33,42$ From the TEM images (Figure S16F from Supporting Information), nanofibrous networks are shown to be 3also in the aqueous surroundings of the droplets, which indicates that both routes play a role in the stabilization of the emulsion, especially at higher concentrations and upon delayed emulsification. The droplet size distribution for the emulsion formed when $6.6 \mu \mathrm{M}$ phosphatase is added to the de-emulsified $\mathrm{KY} p \mathrm{~F}$ mixture after 1 week of storage also followed a normal distribution (Figure S18E and Figure S19E), comparable to when the enzyme was added immediately upon preparation (Table 1). 


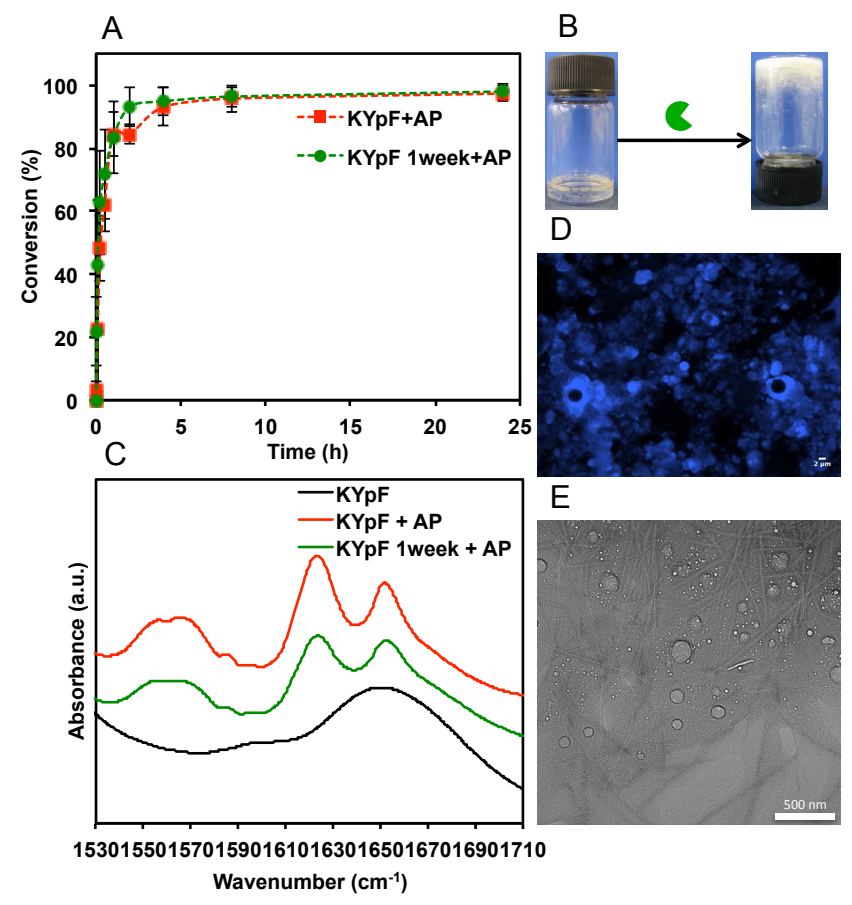

Figure 5. (A) HPLC conversion from KYpF into KYF in buffer/rapeseed oil system when enzyme is added upon preparation and after 1 week storage prior to enzyme addition; (B) Photograph showing the macroscopic appearance of $\mathrm{KYpF}$ biphasic mixture after 1 week storage and after adding the enzyme (6.6 $\mu \mathrm{M}$ alkaline phosphatase); (C) FTIR spectra of aqueous/organic systems of KYpF, when enzyme is added upon preparation and after 1 week storage; (D) Fluorescence microscopy image of the oil-in-water droplets stabilized by KYF fibers when AP is added to KYpF that was stored for one week in fully demulsified form; (E) TEM image of the emulsion formed upon the addition of AP to the 1 week-old KYpF two-phase system.

\section{Thermal unlocking of kinetic emulsions}

The thermal stability of the emulsions was studied for the different samples in order to verify the impact of the kinetics of their formation on their stability (Figure S21, Supporting Information). Upon heating, all samples were shown to coalesce and phase separate after being kept for $30 \mathrm{~min}$ at $50{ }^{\circ} \mathrm{C}$, with the notable exception of $6.6 \mu \mathrm{M} \mathrm{AP}$, which de-emulsified at 60 ${ }^{\circ} \mathrm{C}$ implying increased stability of this emulsion. This shows the highest enzyme concentration produces the most stable emulsions, even though FTIR analysis of the $3.3 \mu \mathrm{M}$ AP sample indicates the latter presents the most well-ordered H-bonded networks. This can be explained by the more entangled nanofibrous networks for the highest enzyme concentration used, which 
can delay droplet coalescence. ${ }^{46-47}$ The 3.3 and $6.6 \mu \mathrm{M}$ enzyme concentration samples were used for a more detailed study on the possibility of de-emulsification and subsequent reemulsification by performing a heat/cool cycle. The biocatalytic self-assembly of fibers in the water/rapeseed oil system was followed by light microscopy (See Supporting Information, Figure $\mathrm{S} 22)$. The $\mathrm{KY} p \mathrm{~F}+6.6 \mu \mathrm{M}$ AP sample shows fiber formation and gelation $1 \mathrm{~h}$ after phosphatase addition and fibers stabilizing droplets $24 \mathrm{~h}$ after, where kinetically trapped structures were possibly formed. In comparison, when $3.3 \mu \mathrm{M}$ enzyme was added to the $\mathrm{KY} p \mathrm{~F}$ in a 9:1 aqueous buffer:rapeseed oil mixture, upon preparation there is no gel-like emulsion formed after $1 \mathrm{~h}$ as it takes longer to form (approximately $2 \mathrm{~h}$ ), but it is visible after $24 \mathrm{~h}$. When these two stable emulsions were incubated at $60{ }^{\circ} \mathrm{C}$ for $1 \mathrm{~h}$, they underwent total disruption of the fibers, which led to droplet coalescence and phase separation (Seen from the photographs of the macroscopic aspect, droplet deformation and size increase present in Figure S22C and S22G, respectively). However, after gradually cooling them down overnight to room temperature and then providing another energy input using the homogenizer, stable gel-like emulsions were again formed (Figure S22D and Figure S22H). 

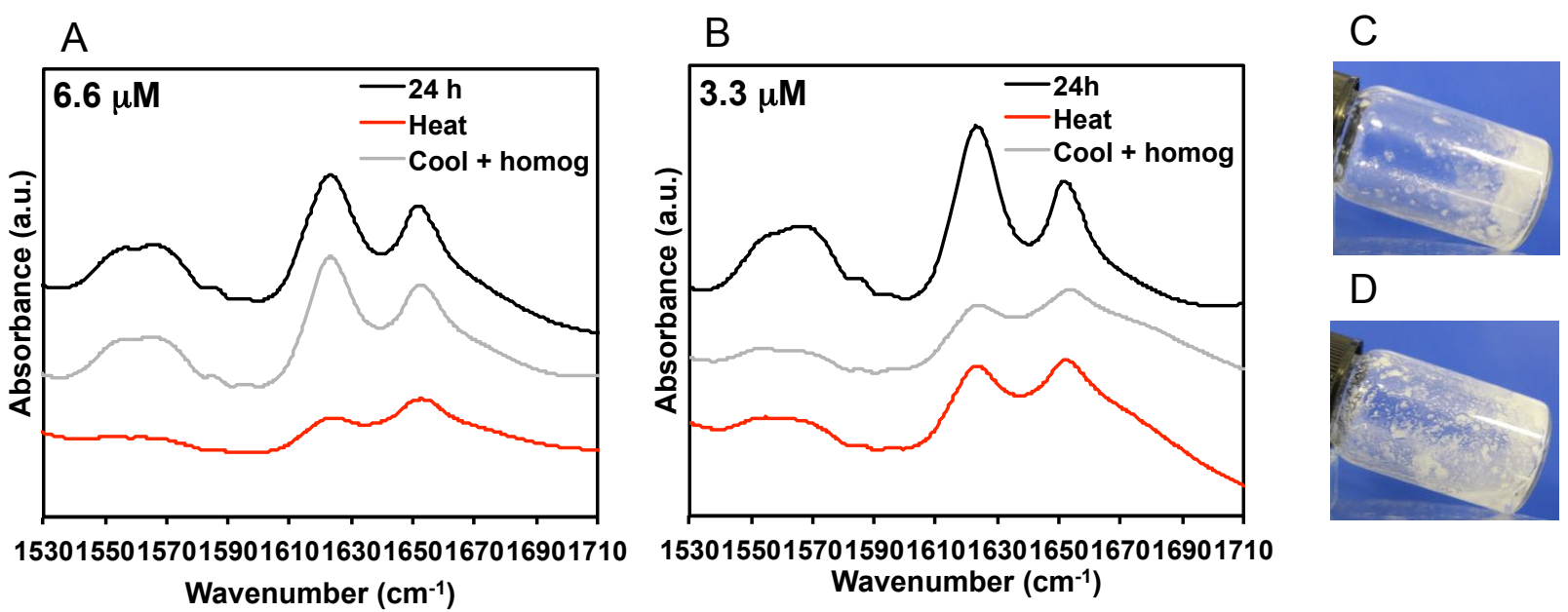

$\mathrm{D}$

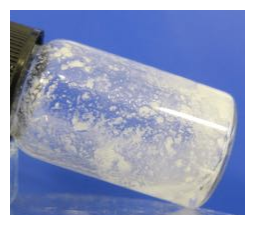

Figure 6. (A) FTIR spectra of the emulsion after $24 \mathrm{~h}$ from the addition of $6.6 \mu \mathrm{M}$ AP, after heated to $60{ }^{\circ} \mathrm{C}$ and after cooled down to room temperature and re-homogenized; (B) FTIR spectra of the emulsion after $24 \mathrm{~h}$ from the addition of $3.3 \mu \mathrm{M}$ AP, after heated to $60{ }^{\circ} \mathrm{C}$ and after cooled down to room temperature and re-homogenized; (CD) Photograph of the macroscopic aspect of the biphasic systems after being heated for 30 min at $40{ }^{\circ} \mathrm{C}$, after having been de-emulsified and re-homogenized again, showing the samples where $6.6 \mu \mathrm{M}$ (C) and $3.3 \mu \mathrm{M}$ AP (D) were used present the same de-emulsifying ability after the kinetically trapped structures are produced.

In order to assess the re-establishment of the H-bonded structures responsible for the fiber formation, FTIR spectroscopy was recorded for the emulsions where 6.6 and $3.3 \mu \mathrm{M}$ AP was used at the key time points (Figure 6A and Figure 6B, respectively). The spectra show disorganization of the $\mathrm{H}$-bonded network when the emulsions were heated up for $1 \mathrm{~h}$ to $60{ }^{\circ} \mathrm{C}$ (red curves), mainly for the sample with $6.6 \mu \mathrm{M}$ AP, for which all the peaks broadened, especially the one at $1550 \mathrm{~cm}^{-1}$, which is characteristic of salt bridges. However, the peaks appear and sharpen after the system is cooled-down to room temperature and homogenized (grey curve), indicating formation of the nanofibers that are able to stabilize $\mathrm{O} / \mathrm{W}$ emulsions again. In order to further understand the impact of the kinetic control over the structures formed and their effect on emulsion stability after heating and then cooling down the samples, the deemulsifying temperature was checked again. Both emulsions were disrupted when heated to 40 ${ }^{\circ} \mathrm{C}$ (Figure 6C for the $6.6 \mu \mathrm{M}$ and Figure 6D for the $3.3 \mu \mathrm{M}$ AP samples). That is, the de- 
emulsifying temperature was found to be the same for both samples, independently of the original enzyme concentration used, after the initial heat/cool cycle. Since, before the heat/cool cycle, they presented different de-emulsifying temperatures $\left(60\right.$ vs. $\left.50{ }^{\circ} \mathrm{C}\right)$, given that these equilibrate after the heat/cool cycle this indicates the rearrangement of the systems to a common state.

\section{CONCLUSION}

In summary, the biocatalytic self-assembly of phosphorylated tripeptide precursors in aqueous buffer into nanofibers was demonstrated, where the biocatalyst amount used is a critical parameter dictating the self-assembly process, which gives rise to pathway dependent nanofibrous networks. When in biphasic mixtures, amphiphilic entangled nanofibrous networks are formed at the aqueous/organic interface and surrounding aqueous phase of the droplets, stabilizing oil-in-water emulsions via interfacial tension decrease and also increased medium viscosity. The tuning of the enzyme concentration used to trigger the self-assembly process of fibers can also be carried out to control emulsion stability by increasing the nanofibrous entangled network that prevents droplet coalescence.

We showed that simple tripeptides can be used as responsive emulsifiers under physiological and unchanged environmental conditions since it is possible to stabilize emulsions on-demand by adding an enzyme. The tunability achieved by using the desired catalyst amount combined with the temporal stimulus given by the possibility of adding the enzymatic stimulus when desired without having to change the conditions is potentially attractive for different cosmetic or food applications. 


\section{MATERIALS AND METHODS}

Materials. H-Lys-Tyr $\left(\mathrm{PO}_{3} \mathrm{H}_{2}\right)-\mathrm{Phe}-\mathrm{OH}$ acetate salt $(\mathrm{KY} p \mathrm{~F})\left(536.16\right.$ g.mol $\left.{ }^{-1}\right)$ was purchased from Bachem at the highest $>97 \%$ purity available and used as supplied. Alkaline phosphatase from bovine, expressed in Pichia pastoris $\left(5379 \mathrm{U} \cdot \mathrm{mg}^{-1}\right.$ protein, $21 \mathrm{mg}$ protein. $\mathrm{mL}^{-1}, 0.044 \mathrm{~mL}$, apparent molar weight $160 \mathrm{kDa}$ ) was supplied by Sigma Aldrich. One enzyme unit corresponds to the quantity of alkaline phosphatase hydrolyzing $1 \mu \mathrm{mol}$ of 4-nitrophenyl phosphate (pNPP) per minute at $\mathrm{pH} 9.8$ and $37^{\circ} \mathrm{C}$.

Preparation of aqueous and biphasic samples. $40 \mathrm{mM} \mathrm{KYpF}$ was dissolved in $1 \mathrm{~mL} \mathrm{pH} 80.1$ M sodium phosphate buffer, a constant volume of $50 \mu \mathrm{L}$ was added from different dilutions of alkaline phosphatase buffered solution to achieve a final AP concentration between $0 \mathrm{U} \cdot \mathrm{mL}^{-1}$

(for the precursor control) and 55.2 U.mL ${ }^{-1}$ (which corresponds to a scale of $0-1.1 \mathrm{mg} \cdot \mathrm{mL}^{-1}$ or 0-6.6 $\mu \mathrm{M})$ and vortexed for $1 \mathrm{~min}$. For the biphasic systems, $100 \mu \mathrm{L}$ rapeseed oil was added to $900 \mu \mathrm{L} 40 \mathrm{mM} \mathrm{KYpF}$ in aqueous buffer. After the same volume of different enzyme dilutions was added to each sample, they were homogenized in a VWR VDI 12 S2 top-bench homogenizer at speed 6 for 10 seconds. All samples were left for $24 \mathrm{~h}$ before characterization was carried out except otherwise stated.

HPLC conversion. To monitor the dephosphorylation by alkaline phosphatase, aliquots of 25 $\mu \mathrm{L}$ were taken at different times after the addition of alkaline phosphatase $(\mathrm{t}=0 \mathrm{~h})$ and diluted in $500 \mu \mathrm{L}$ of $50 \%$ acetonitrile solution containing $0.1 \%$ TFA. An aliquot of $50 \mu \mathrm{L}$ from each diluted sample was injected on a Dionex P680 system with a Macherrey-Nagel $250 \mathrm{~mm} 4.6 \mathrm{~mm}$ C18 column for reversed phase HPLC. The mobile phase was comprised of water and acetonitrile at a flow rate of $1 \mathrm{~mL} \cdot \mathrm{min}^{-1}$. The gradient was linear to $20 \%(\mathrm{v} / \mathrm{v})$ acetonitrile in 
water at 4 minutes, gradually rising to $80 \%(\mathrm{v} / \mathrm{v})$ acetonitrile in water at 35 minutes and decreasing it to $20 \%$ acetonitrile in water at $42 \mathrm{~min}$. The area of the peptide peaks was analysed using a UVD170U UV-Vis detector at a $265 \mathrm{~nm}$ wavelength to calculate the conversion and the average of triplicates is shown.

Fluorescence Spectroscopy. Fluorescence emission spectra were recorded between 250 and $600 \mathrm{~nm}$ with an excitation wavelength of $274 \mathrm{~nm}$ (for tyrosine) at medium response, $3 \mathrm{~nm}$ bandwidth and $1 \mathrm{~nm}$ data pitch. Fluorescence emission spectra were measured on a Jasco FP6500 spectrofluorometer with light measured orthogonally to the excitation light with a scanning speed of $500 \mathrm{~nm} \cdot \mathrm{min}^{-1}$. The samples were immediately placed in a cuvette and measured, with no dilution, at different times after the addition of alkaline phosphatase (which was set as $\mathrm{t}=0 \mathrm{~h})$.

IR Spectroscopy. FT-IR spectra were recorded on a Bruker Optics Vertex 70 spectrophotometer. Measurements were performed in a standard IR cell holder (Harrick Scientific), in which the sample was placed between two $\mathrm{CaF}_{2}$ windows separated by a $50 \mathrm{~mm}$ PTFE spacer. The spectra were acquired in the region 1530 and $1710 \mathrm{~cm}^{-1}$ over 25 scans at a resolution of $1 \mathrm{~cm}^{-1} \cdot \mathrm{pH} 80.1 \mathrm{M}$ deuterated oxide phosphate buffer was used to prepare the samples and the curves background corrected.

Rheology. Rheological properties of the different samples were assessed using a Malvern Kinexus rheometer with temperature controlled at $20^{\circ} \mathrm{C}$ and a $20 \mathrm{~mm}$ parallel plate geometry with a gap of $0.9 \mathrm{~mm}$. Before any measurement, amplitude sweeps were performed at constant frequency of $1 \mathrm{~Hz}$ from shear strain $0.01-100 \%$ to ensure work at the linear viscoelastic regime. Oscillatory rheology was performed $24 \mathrm{~h}$ after sample preparation by carefully loading 
the gel-type samples on to the rheometer with a spatula and no dilution. Triplicates were carried out for all the samples and the average data is shown.

TEM. For the aqueous samples, carbon-coated copper grids (300 mesh) were glow discharged in vacuum for 10-15 seconds, the support films were touched onto them, blotted with filter paper and settled for 30 seconds. $1 \%$ aqueous methylamine vanadate obtained from Nanovan, Nanoprobes was used as a negative stain, the samples dried for 10 minutes and imaged using a FEI TECNAI TEO microscope operating at $200 \mathrm{kV}$. For the biphasic systems, carbon-coated copper grids (400 mesh) were used and also glow discharged. Then each sample was dropped into the grid, blotted, dropped Nanovan and blotted till dry. They were then imaged using a FEI Titan Halo microscope at $300 \mathrm{kV}$.

Fluorescence Microscopy. The oil-in-water droplets were imaged on an Upright Epifluorescent Microscope (Nikon, Eclipse E600) after being transferred from the emulsion layer onto a glass slide, which was covered with a coverslip and mounted. $1 \mathrm{mg} \cdot \mathrm{mL}^{-1}$ Thioflavin $\mathrm{T}$ (ThT) in $0.1 \mathrm{M} \mathrm{pH} 8$ phosphate buffer was used to prepare the samples, to label the aqueous phase in the emulsion layers and the self-assembled peptides. Images were acquired using Zeiss 10x, 20x dry objectives and 40x, 60x, 100x oil objectives. An appropriate DAPI filter was used.

Light microscopy. The emulsions were pipetted into a glass slide, covered with a coverslip and mounted in a fluorescence microscope (Eclipse LV 100 Nikon, Vienna, Austria) with an optical filter of $438 / 22 \mathrm{~nm}$, a dichromatic mirror $458 \mathrm{~nm}$ and a filter for detection of the fluorescence at 483/32nm. The images were recorded with a black and white Photometric Coolsnap HQ camera (Photometrics, Tucson, USA). 20x and 50x objectives were used. 
UV/Vis. For the enzymatic activity assay, $850 \mu \mathrm{L}$ of buffer (or mixture of buffer and organic solvent according to each volume ratio), $100 \mu \mathrm{L}$ of $100 \mathrm{mM}$ pNPP phosphatase substrate and 50 $\mu \mathrm{L}$ of enzyme were placed into a cuvette, giving a final phosphatase concentration of $1.4 \mathrm{U}^{\mathrm{mL}}$ ${ }^{1}$. The dephosphorylation reaction was then monitored by UV-Vis by recording the absorbance at $405 \mathrm{~nm}$ every $1 \mathrm{~min}$ for $10 \mathrm{~min}$, since $\mathrm{p}$-nitrophenol is a chromogenic product that absorbs at $405 \mathrm{~nm}$. Spectra were recorded between 250 and $400 \mathrm{~nm}$ on a Jasco UV-660 spectrophotometer and the average of triplicates by the subtraction of each corresponding blank shown.

CG/MD simulations. Molecular dynamics simulations were carried out in GROMACS 4.5.38 using MARTINI force field (version 2.2) ${ }^{49}$. The model used for KYF is identical to the KYF modelled previously, ${ }^{33}$ while the phosphorylated KYF calculations involved the addition of a new bead to the Martini force field. The parameterization of the mentioned phosphorylated tyrosine for $\mathrm{KY} p \mathrm{~F}$ is fully described in Supporting Information. A cubic box of $13 \times 13 \times 13$ $\mathrm{nm}^{3}$ containing 300 zwitterionic tripeptides was created, neutralized and filled with standard CG water. This box was minimized for 5000 steps and equilibrated for 500 million steps of 20 fs timestep, giving $10 \mu \mathrm{s}$ simulation time using the Berendsen algorithms ${ }^{50}$ to keep temperature and pressure around $303 \mathrm{~K}$ and 1 bar, respectively. 


\section{ASSOCIATED CONTENT}

Supporting Information. The detailed fluorescence spectroscopy plots showing red-shifts, detailed HPLC conversion rates, FTIR spectroscopy controls, Phosphate bead parameterization for CG/MD simulations, TEM images of samples, including the non-enzymatically formed KYF, detailed rheology graphs including strain sweeps, enzyme activity assay in different solvent systems, TEM images of other emulsions, emulsion droplet size analysis, thermal stability and light microscope images are presented in Supporting Information.

\section{AUTHOR INFORMATION}

\section{Corresponding Author}

Dr. Tell Tuttle, tell.tuttle@strath.ac.uk

Prof. Rein V. Ulijn. rein.ulijn@asrc.cuny.edu

\section{ACKNOWLEDGMENT}

We acknowledge Margaret Mullin from the University of Glasgow for the TEM on the aqueous samples and Dr. Tong Wang from ASRC for the help using TEM on the biphasic samples. We are also thankful to Dr. Neil Hunt for being able to use the FTIR equipment and to Gillian Robb for using the fluorescence microscope. Results were obtained using the EPSRC funded ARCHIE-WeSt High Performance Computer (www.archie-west.ac.uk; EPSRC grant no. $\mathrm{EP} / \mathrm{K} 000586 / 1)$. The authors acknowledge the financial support by the EC $7^{\text {th }}$ Framework Programme Marie Curie Actions via the European Initial Training Network SMARTNET. 


\section{REFERENCES}

1. Liu, Y.; Jessop, P. G.; Cunningham, M.; Eckert, C. A.; Liotta, C. L., Switchable surfactants. Science 2006, 313 (5789), 958-960.

2. Zhu, Y.; Jiang, J.; Cui, Z.; Binks, B. P., Responsive aqueous foams stabilised by silica nanoparticles hydrophobised in situ with a switchable surfactant. Soft matter 2014, 10 (48), 9739-9745.

3. Patel, A. R.; Drost, E.; ten Hoorn, J. S.; Velikov, K. P., Fabrication and characterization of emulsions with pH responsive switchable behavior. Soft Matter 2013, 9 (29), 6747-6751.

4. Balasuriya, T. S.; Dagastine, R. R., Interaction forces between bubbles in the presence of novel responsive peptide surfactants. Langmuir 2012, 28 (50), 17230-17237.

5. Malcolm, A. S.; Dexter, A. F.; Middelberg, A. P., Foaming properties of a peptide designed to form stimuli-responsive interfacial films. Soft Matter 2006, 2 (12), 1057-1066.

6. Malcolm, A. S.; Dexter, A. F.; Middelberg, A. P., Peptide surfactants (Pepfactants) for switchable foams and emulsions. Asia-Pacific Journal of Chemical Engineering 2007, 2 (5), 362-367.

7. Fameau, A. L.; Saint-Jalmes, A.; Cousin, F.; Houinsou Houssou, B.; Novales, B.; Navailles, L.; Nallet, F.; Gaillard, C.; Boué, F.; Douliez, J. P., Smart foams: switching reversibly between ultrastable and unstable foams. Angewandte Chemie International Edition 2011, 50 (36), 8264-8269.

8. Chevallier, E.; Monteux, C.; Lequeux, F.; Tribet, C., Photofoams: remote control of foam destabilization by exposure to light using an azobenzene surfactant. Langmuir 2012, 28 (5), 2308-2312.

9. Fairman, R.; Åkerfeldt, K. S., Peptides as novel smart materials. Current Opinion in Structural Biology 2005, 15 (4), 453-463.

10. Mart, R. J.; Osborne, R. D.; Stevens, M. M.; Ulijn, R. V., Peptide-based stimuliresponsive biomaterials. Soft Matter 2006, 2 (10), 822-835.

11. Zhang, S., Fabrication of novel biomaterials through molecular self-assembly. Nature biotechnology 2003, 21 (10), 1171-1178.

12. Fleming, S.; Ulijn, R. V., Design of nanostructures based on aromatic peptide amphiphiles. Chemical Society Reviews 2014, 43 (23), 8150-8177.

13. Tao, K.; Levin, A.; Adler-Abramovich, L.; Gazit, E., Fmoc-modified amino acids and short peptides: simple bio-inspired building blocks for the fabrication of functional materials. Chemical Society Reviews 2016.

14. Cui, H.; Webber, M. J.; Stupp, S. I., Self-assembly of peptide amphiphiles: From molecules to nanostructures to biomaterials. Peptide Science 2010, 94 (1), 1-18.

15. Ryan, D. M.; Nilsson, B. L., Self-assembled amino acids and dipeptides as noncovalent hydrogels for tissue engineering. Polymer Chemistry 2012, 3 (1), 18-33.

16. Adams, D. J.; Holtzmann, K.; Schneider, C.; Butler, M. F., Self-assembly of surfactantlike peptides. Langmuir 2007, 23 (25), 12729-12736.

17. Roberts, D.; Rochas, C.; Saiani, A.; Miller, A., Effect of peptide and guest charge on the structural, mechanical and release properties of $\beta$-sheet forming peptides. Langmuir 2012, 28 (46), 16196-16206.

18. Yang, Z.; Gu, H.; Fu, D.; Gao, P.; Lam, J. K.; Xu, B., Enzymatic Formation of Supramolecular Hydrogels. Advanced Materials 2004, 16 (16), 1440-1444. 
19. Yang, Z.; Liang, G.; Xu, B., Enzymatic control of the self-assembly of small molecules: a new way to generate supramolecular hydrogels. Soft Matter 2007, 3 (5), 515-520.

20. Wang, W.; Yang, Z.; Patanavanich, S.; Xu, B.; Chau, Y., Controlling self-assembly within nanospace for peptide nanoparticle fabrication. Soft Matter 2008, 4 (8), 1617-1620.

21. Webber, M. J.; Newcomb, C. J.; Bitton, R.; Stupp, S. I., Switching of self-assembly in a peptide nanostructure with a specific enzyme. Soft Matter 2011, 7 (20), 9665-9672.

22. Boekhoven, J.; Poolman, J. M.; Maity, C.; Li, F.; van der Mee, L.; Minkenberg, C. B.; Mendes, E.; van Esch, J. H.; Eelkema, R., Catalytic control over supramolecular gel formation. Nature chemistry 2013, 5 (5), 433-437.

23. Hirst, A. R.; Roy, S.; Arora, M.; Das, A. K.; Hodson, N.; Murray, P.; Marshall, S.; Javid, N.; Sefcik, J.; Boekhoven, J.; van Esch, J. H.; Santabarbara, S.; Hunt, N. T.; Ulijn, R. V., Biocatalytic induction of supramolecular order. Nature chemistry 2010, 2 (12), 1089-94.

24. Yucel, T.; Micklitsch, C. M.; Schneider, J. P.; Pochan, D. J., Direct observation of earlytime hydrogelation in $\beta$-hairpin peptide self-assembly. Macromolecules 2008, 41 (15), 57635772.

25. Ozbas, B.; Kretsinger, J.; Rajagopal, K.; Schneider, J. P.; Pochan, D. J., Salt-triggered peptide folding and consequent self-assembly into hydrogels with tunable modulus.

Macromolecules 2004, 37 (19), 7331-7337.

26. Veerman, C.; Rajagopal, K.; Palla, C. S.; Pochan, D. J.; Schneider, J. P.; Furst, E. M., Gelation kinetics of $\beta$-hairpin peptide hydrogel networks. Macromolecules 2006, 39 (19), 66086614.

27. Niece, K. L.; Czeisler, C.; Sahni, V.; Tysseling-Mattiace, V.; Pashuck, E. T.; Kessler, J. A.; Stupp, S. I., Modification of gelation kinetics in bioactive peptide amphiphiles.

Biomaterials 2008, 29 (34), 4501-4509.

28. Wang, J.; Liu, K.; Xing, R.; Yan, X., Peptide self-assembly: thermodynamics and kinetics. Chemical Society Reviews 2016.

29. Tena-Solsona, M.; Escuder, B.; Miravet, J. F.; Casttelleto, V.; Hamley, I. W.; Dehsorkhi, A., Thermodynamic and Kinetic Study of the Fibrillization of a Family of Tetrapeptides and Its Application to Self-Sorting. What Takes So Long? Chemistry of Materials 2015, 27 (9), 3358-3365.

30. Moreira, I. P.; Sasselli, I. R.; Cannon, D. A.; Hughes, M.; Lamprou, D. A.; Tuttle, T.; Ulijn, R. V., Enzymatically activated emulsions stabilised by interfacial nanofibre networks. Soft Matter 2016, 12 (9), 2623-2631.

31. Frederix, P. W.; Scott, G. G.; Abul-Haija, Y. M.; Kalafatovic, D.; Pappas, C. G.; Javid, N.; Hunt, N. T.; Ulijn, R. V.; Tuttle, T., Exploring the sequence space for (tri-) peptide selfassembly to design and discover new hydrogels. Nature chemistry 2014.

32. Marchesan, S.; Easton, C. D.; Kushkaki, F.; Waddington, L.; Hartley, P. G., Tripeptide self-assembled hydrogels: unexpected twists of chirality. Chemical Communications 2012, 48 (16), 2195-2197.

33. Scott, G. G.; McKnight, P. J.; Tuttle, T.; Ulijn, R. V., Emulsifiers: Tripeptide Emulsifiers (Adv. Mater. 7/2016). Advanced Materials 2016, 28 (7), 1329-1329.

34. Yang, Z.; Liang, G.; Ma, M.; Gao, Y.; Xu, B., In Vitro and In Vivo Enzymatic Formation of Supramolecular Hydrogels Based on Self-Assembled Nanofibers of a $\beta$-Amino Acid Derivative. Small 2007, 3 (4), 558-562.

35. Decker, L. A.; Corporation, W. B., Worthington Enzyme Manual: Enzymes, Enzyme Reagents, Related Biochemicals. Worthington Biochemical Corporation: 1977. 
36. Thornton, K.; Smith, A.; Merry, C. R.; Ulijn, R., Controlling stiffness in nanostructured hydrogels produced by enzymatic dephosphorylation. Biochemical society transactions $\mathbf{2 0 0 9}$, 37 (4), 660.

37. Fleming, S.; Frederix, P. W. J. M.; Ramos Sasselli, I.; Hunt, N. T.; Ulijn, R. V.; Tuttle, T., Assessing the Utility of Infrared Spectroscopy as a Structural Diagnostic Tool for $\beta$-Sheets in Self-Assembling Aromatic Peptide Amphiphiles. Langmuir 2013, 29 (30), 9510-9515.

38. Yan, C.; Pochan, D. J., Rheological properties of peptide-based hydrogels for biomedical and other applications. Chemical Society Reviews 2010, 39 (9), 3528-3540.

39. Cheng, G.; Castelletto, V.; Moulton, C.; Newby, G.; Hamley, I., Hydrogelation and selfassembly of Fmoc-tripeptides: unexpected influence of sequence on self-assembled fibril structure, and hydrogel modulus and anisotropy. Langmuir 2010, 26 (7), 4990-4998.

40. Hughes, M.; Birchall, L. S.; Zuberi, K.; Aitken, L. A.; Debnath, S.; Javid, N.; Ulijn, R. V., Differential supramolecular organisation of Fmoc-dipeptides with hydrophilic terminal amino acid residues by biocatalytic self-assembly. Soft Matter 2012, 8 (45), 11565-11574.

41. Guilbaud, J.-B.; Rochas, C.; Miller, A. F.; Saiani, A., Effect of enzyme concentration of the morphology and properties of enzymatically triggered peptide hydrogels.

Biomacromolecules 2013, 14 (5), 1403-1411.

42. Bai, S.; Pappas, C.; Debnath, S.; Frederix, P. W. J. M.; Leckie, J.; Fleming, S.; Ulijn, R. V., Stable Emulsions Formed by Self-Assembly of Interfacial Networks of Dipeptide Derivatives. ACS nano 2014, 8 (7), 7005-7013.

43. Solans, C.; Pons, R.; Zhu, S.; Davis, H. T.; Evans, D. F.; Nakamura, K.; Kunieda, H., Studies on macro-and microstructures of highly concentrated water-in-oil emulsions (gel emulsions). Langmuir 1993, 9 (6), 1479-1482.

44. Li, Z.; Ming, T.; Wang, J.; Ngai, T., High internal phase emulsions stabilized solely by microgel particles. Angewandte Chemie International Edition 2009, 48 (45), 8490-8493.

45. Laupheimer, M.; Jovic, K.; Antunes, F. E.; Miguel, M. d. G. M.; Stubenrauch, C., Studying orthogonal self-assembled systems: phase behaviour and rheology of gelled microemulsions. Soft Matter 2013, 9 (13), 3661-3670.

46. Izmailova, V.; Yampolskaya, G.; Tulovskaya, Z., Development of the Rehbinder's concept on structure-mechanical barrier in stability of dispersions stabilized with proteins. Colloids and Surfaces A: Physicochemical and Engineering Aspects 1999, 160 (2), 89-106. 47. Wilde, P., Interfaces: their role in foam and emulsion behaviour. Current Opinion in Colloid \& Interface Science 2000, 5 (3), 176-181.

48. Hess, B.; Kutzner, C.; Van Der Spoel, D.; Lindahl, E., GROMACS 4: algorithms for highly efficient, load-balanced, and scalable molecular simulation. Journal of chemical theory and computation 2008, 4 (3), 435-447.

49. Marrink, S. J.; Risselada, H. J.; Yefimov, S.; Tieleman, D. P.; De Vries, A. H., The MARTINI force field: coarse grained model for biomolecular simulations. The Journal of Physical Chemistry B 2007, 111 (27), 7812-7824.

50. Berendsen, H. J.; Postma, J. v.; van Gunsteren, W. F.; DiNola, A.; Haak, J., Molecular dynamics with coupling to an external bath. The Journal of chemical physics 1984, 81 (8), 3684-3690. 
TOC Graphic

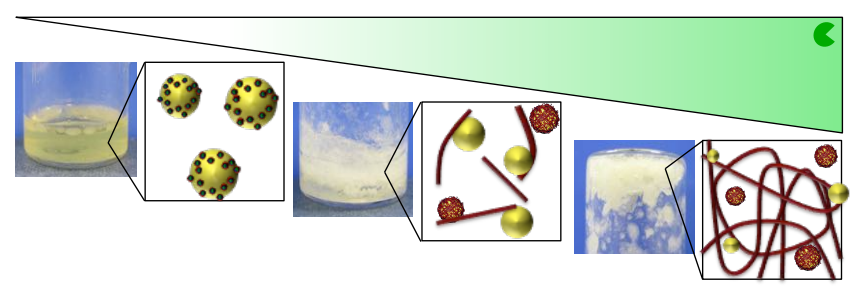




\section{Supporting Information}

\section{Biocatalytic self-assembly of tripeptide gels and emulsions}

Inês P. Moreira ${ }^{1}$, Tomasz K. Piskorz ${ }^{2}$, Jan H. van Esch ${ }^{2}$, Tell Tuttle ${ }^{1}$, Rein V. Ulijn ${ }^{1,3,4,5}$

${ }^{1}$ WestCHEM, Department of Pure and Applied Chemistry, University of Strathclyde, 295 Cathedral Street, Glasgow G1 1XL, UK

${ }^{2}$ Department of Chemical Engineering, Delft University of Technology, van der Maasweg, 2629 HZ Delft, The Netherlands

${ }^{3}$ Advanced Science Research Center (ASRC), City University of New York, 85 St Nicholas Terrace, New York NY10031, USA

${ }^{4}$ Department of Chemistry and Biochemistry, City University of New York - Hunter College, 695 Park Ave., New York, NY 10065, USA

${ }^{5} \mathrm{PhD}$ Programs in Chemistry and Biochemistry, The Graduate Center of the City University of New York, New York, NY 10016, USA

\section{Corresponding Author}

Dr. Tell Tuttle, tell.tuttle@strath.ac.uk

Prof. Rein V. Ulijn, rein.ulijn@asrc.cuny.edu 

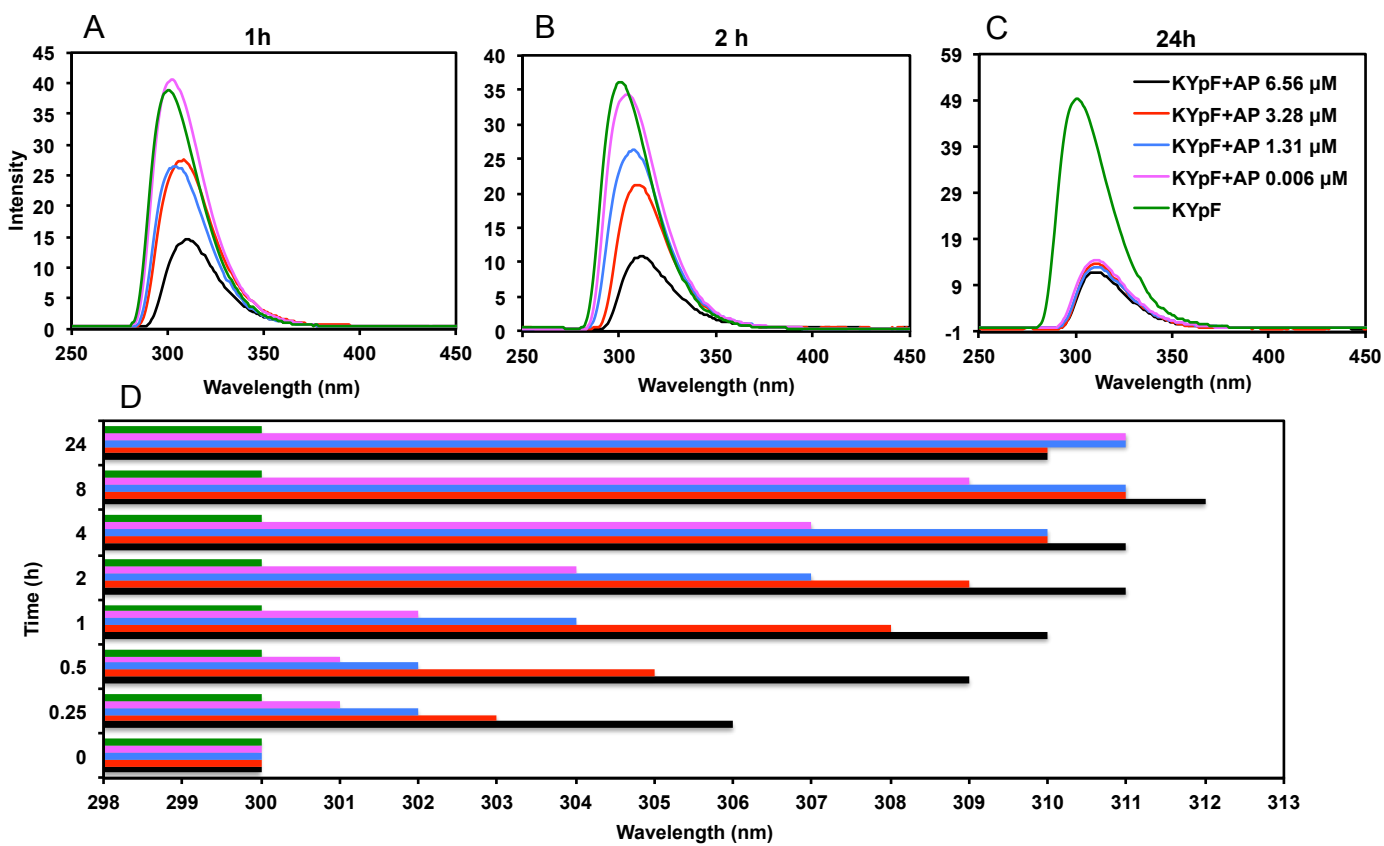

Figure S1. Fluorescence emission spectra of the different samples $1 \mathrm{~h}$ after the addition of alkaline phosphatase in different amounts (A); $2 \mathrm{~h}$ after (B); and after $24 \mathrm{~h}$ of enzyme addition (C); (D) Redshift of maximum tyrosine wavelength at different time points for the various enzyme concentration samples. 


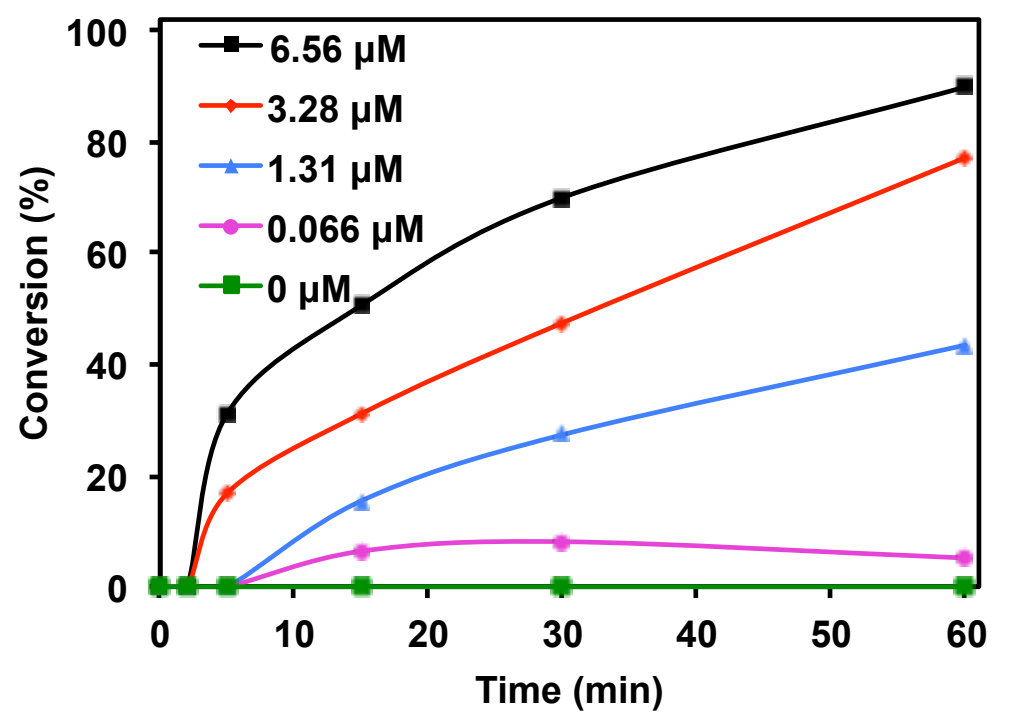

Figure S2. Detailed conversion at the first $60 \mathrm{~min}$ from the moment alkaline phosphatase is added, at different concentrations. 

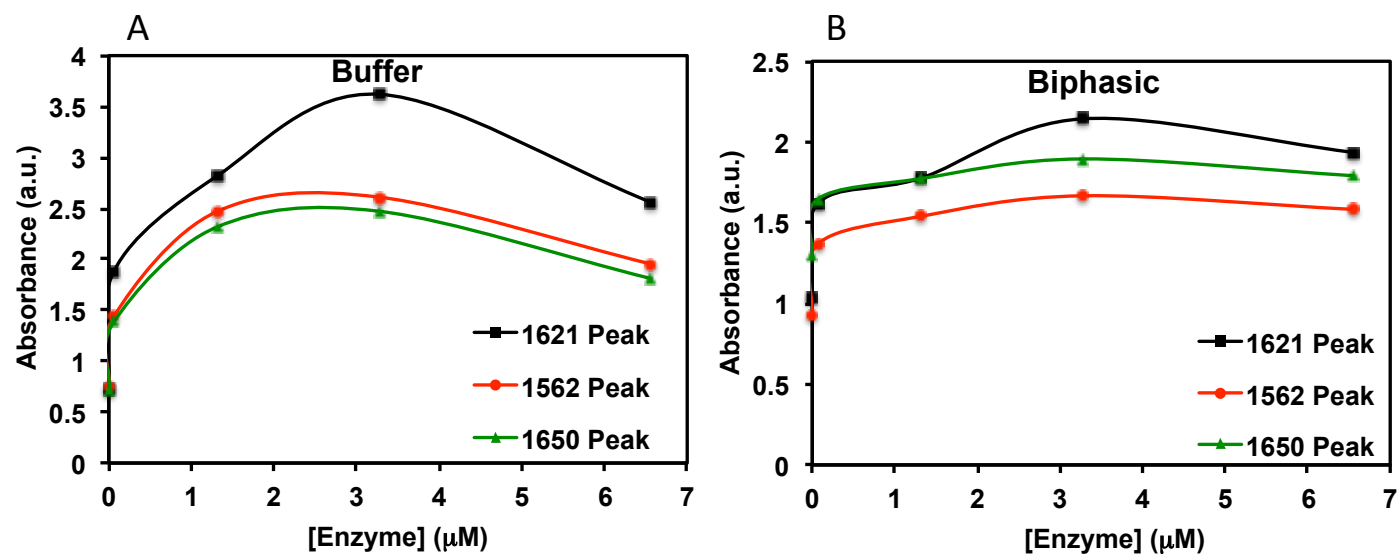

Figure S3. Absorbance maximum at specific wavenumbers from FTIR spectra versus alkaline phosphatase concentration used. 


\section{Parameterization of phosphorylated tyrosine for CG-MD simulations}

Parameterizing phosphorylated tyrosine (TYP) was carried out by initially adding a Qa bead (charged bead with H-acceptor capacity) to tyrosine (TYR) followed by an iterative process. A -2 charge was used for the initial Qa bead since the phosphate group is present in its $\mathrm{HPO}_{4}{ }^{2-}$ form when at $\mathrm{pH}$ 8. To determine the bonded parameters to assign to it, atomistic simulations of one molecule of each were run in water for $20 \mathrm{~ns}$ and mapped into coarse-grained representation by defining the center of mass of the atoms corresponding to each mapped coarse-grained bead, as represented in the Figure below.
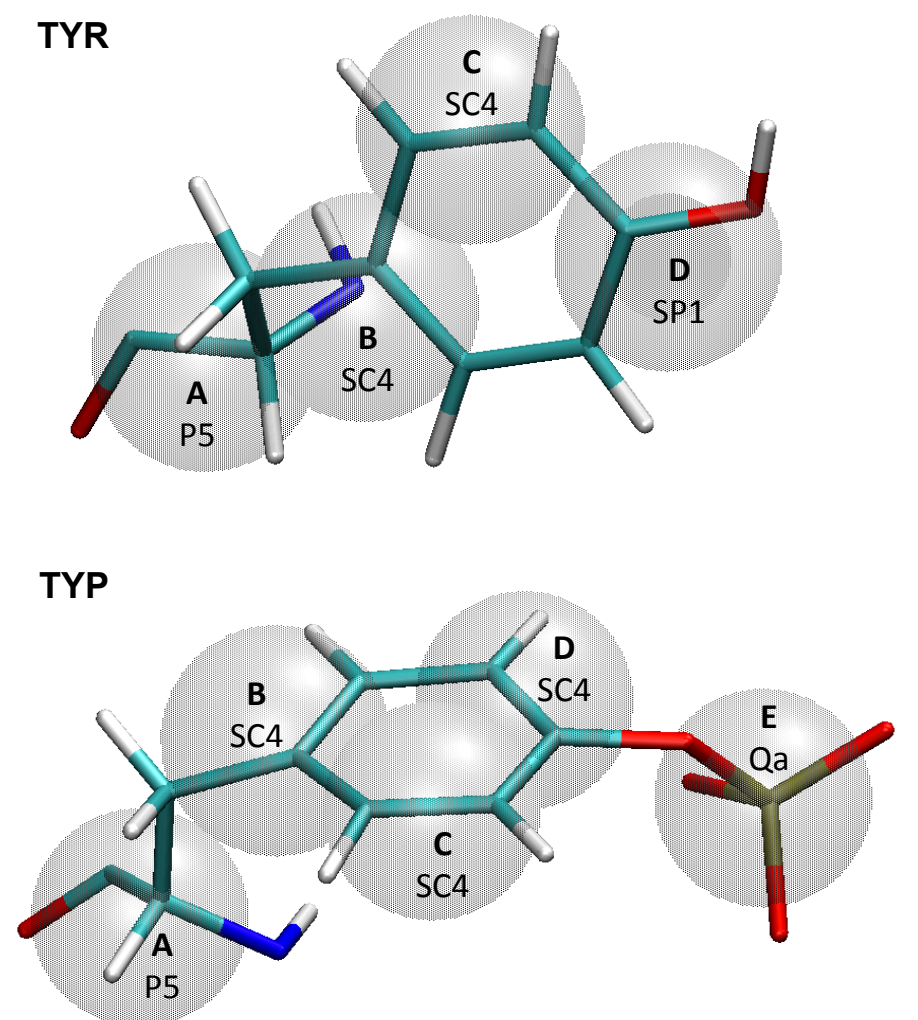

Figure S4. Schematic representation of atomistic to coarse-grained molecule of tyrosine, TYR and phospho-tyrosine, TYP.

The distribution functions for bond lengths, bond angles and dihedral angles were calculated for the TYR residue in KYpF and compared to the standard TYR in KYF (Figure S5), for which bonded parameters were previously assigned by Marrink et al. ${ }^{1}$ 

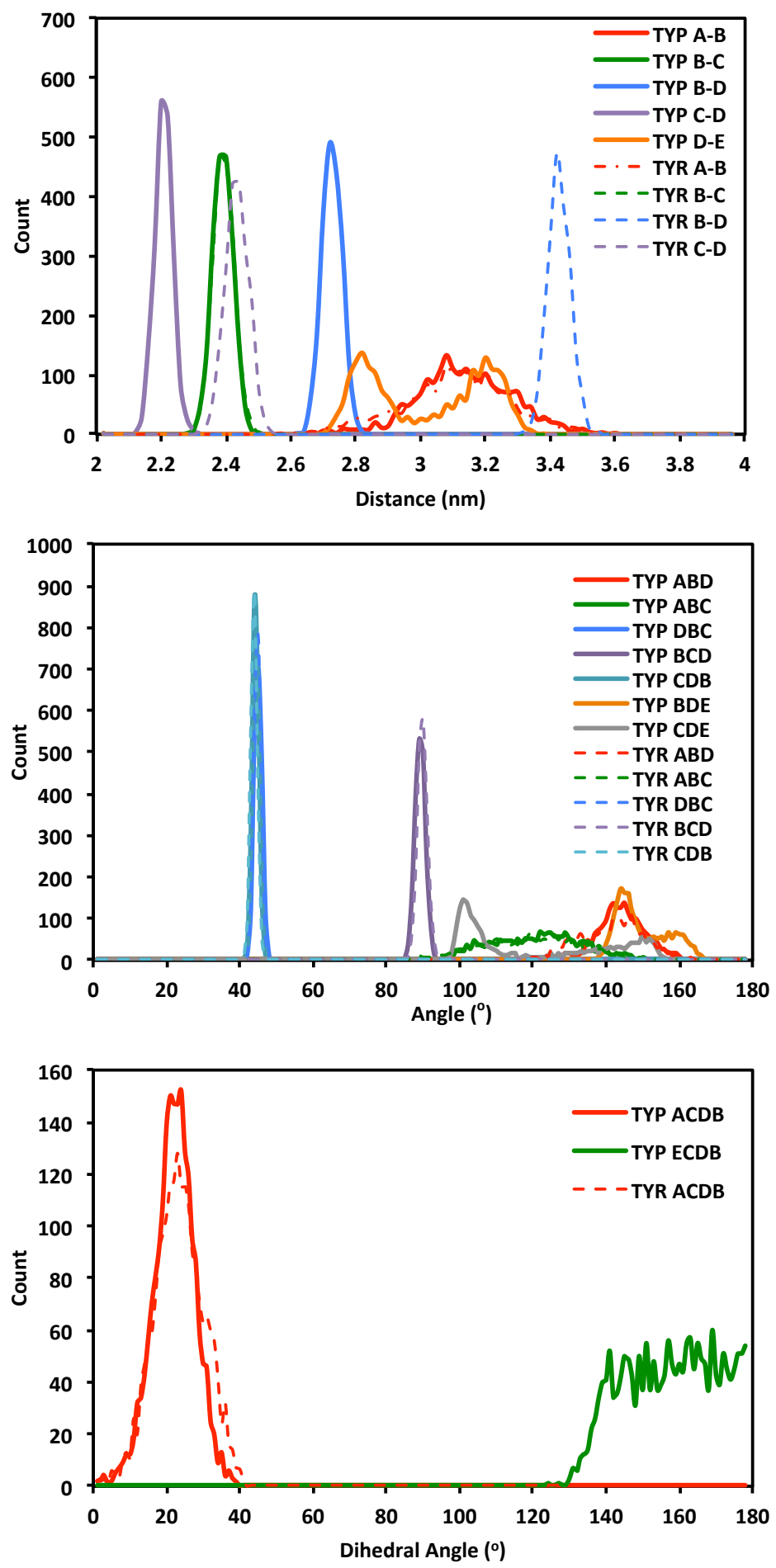

Figure S5. Distribution functions of bonds, angles and dihedral angles for TYP and TYR, based on atomistic simulations of $\mathrm{KYpF}$ and $\mathrm{KYF}$.

The mass of the bead is set to be the same as any other CG bead (72 amu), the backbone-side chain (and side chain-side chain) bonded parameters were kept from TYR parameters, such as for example the constraints for the ring beads. The bond length and angle including the E (Qa) bead was taken from the average between the 
two appearing peaks, following the methodology followed by the creators of Martini. These parameters were added to the martinize.py script ${ }^{1-3}$ to create a Gromacs topology file as below for phosphorylated tyrosine (TYP):

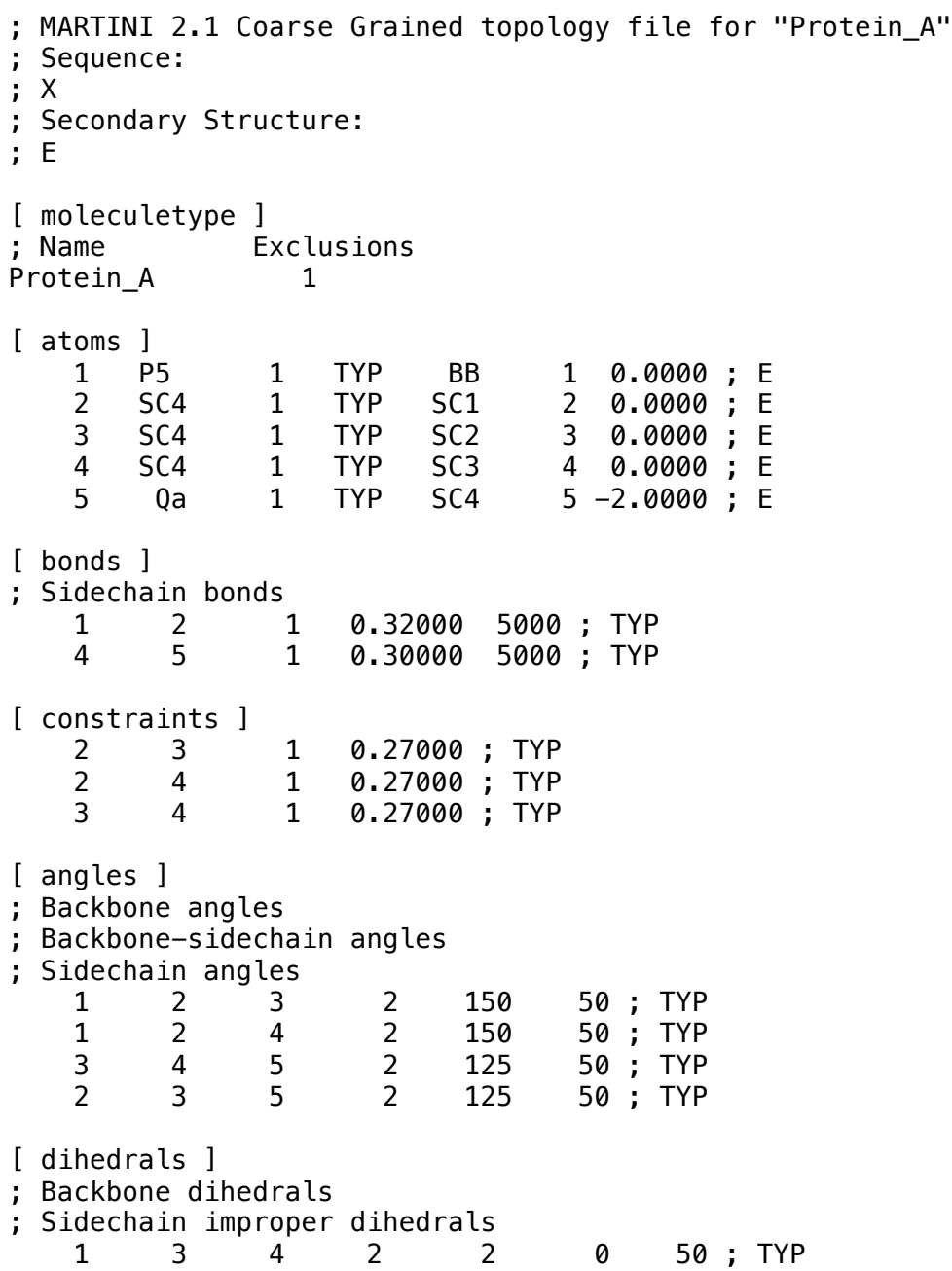

$\begin{array}{llllll}2 & 3 & 1 & 0.27000 ; & \text { TYP } \\ 2 & 4 & 1 & 0.27000 ; & \text { TYP } \\ 3 & 4 & 1 & 0.27000 ; & \text { TYP }\end{array}$

[ angles ]

; Backbone angles

; Backbone-sidechain angles

; Sidechain angles

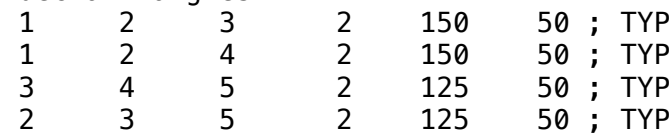

[ dihedrals ]

; Backbone dihedrals

; Sidechain improper dihedrals

$\begin{array}{lllllll}1 & 3 & 4 & 2 & 2 & 0 & 50 \text {; TYP }\end{array}$

knowing that the topology file for tyrosine (TYR) is the following:

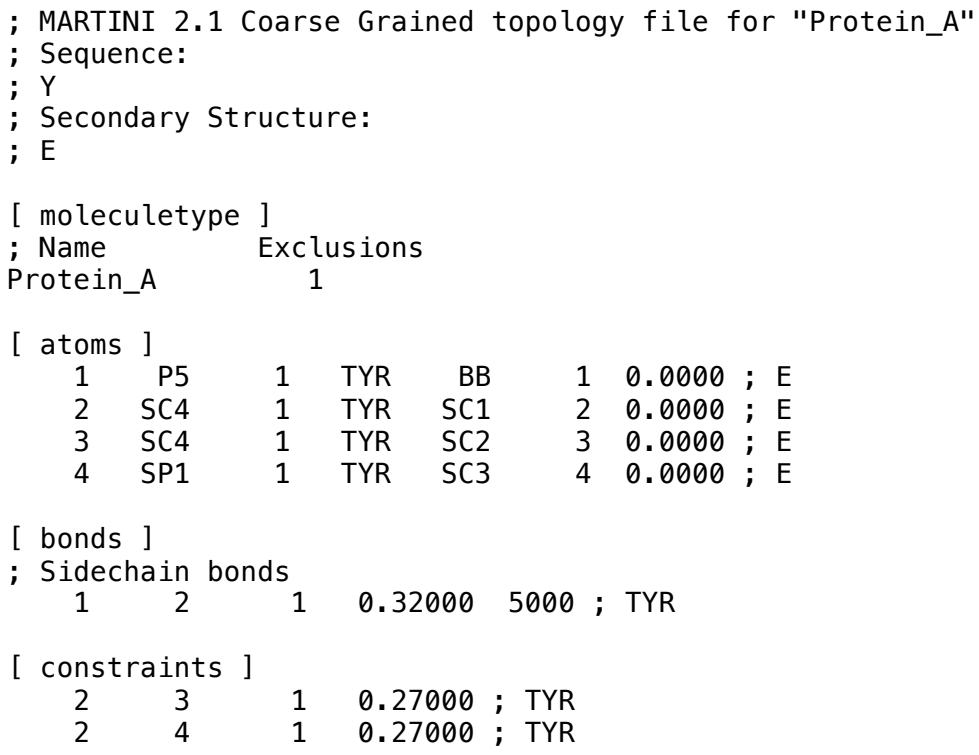




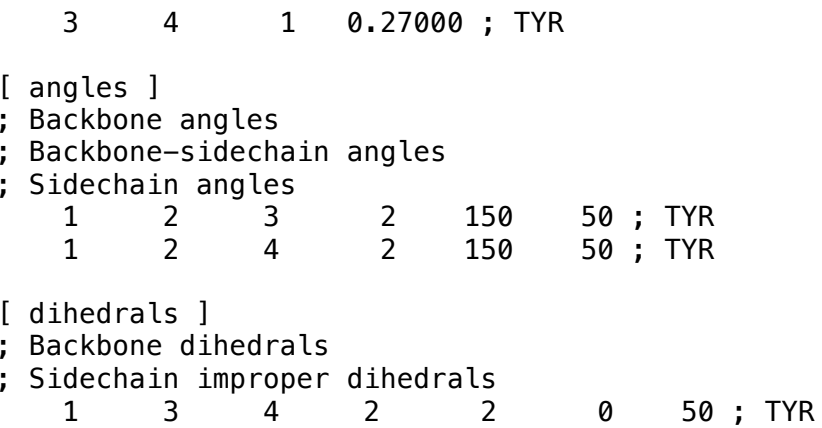

In order to validate this parameterization, partition coefficients were determined using a computational and an experimental technique.

\section{Partition coefficient using umbrella sampling and WHAM method (CG-MD)}

Each amino acid was placed, separately, in a water/octanol box of $15 \times 5 \times 5 \mathrm{~nm}^{3}$, centered in the water phase and neutralized. It was then minimised with the steepest crescent technique for 5000 steps, gradually heated from 0 to $300 \mathrm{~K}$ for 60 ps under a NVT ensemble and equilibrated at $300 \mathrm{~K}$ and 1 bar for 60 ps under NPT conditions. It was then pulled through the longest $\mathrm{x}$-axis $(0.002 \mathrm{~nm} / \mathrm{ps}$ pull rate $)$ from water to octanol for $4.5 \mathrm{~ns}$ using umbrella sampling. The trajectory was saved every $30 \mathrm{ps}$ and each frame was sampled and equilibrated under NPT ensemble for 150 ps and ran for 9 ns. The analysis of the free energies was carried out using the Weighted Histogram Analysis Method g_wham incorporated in Gromacs package. ${ }^{4}$

The partition free energy $\Delta G_{\mathrm{L}}$ and the partition coefficient $K_{a w}$ are related by the equation 1:

$$
\Delta G_{\mathrm{LW}}=-2.303 \mathrm{RT} \log \mathrm{K}_{\mathrm{aw}}
$$

When analyzing the free energy graphs below, the solute starts being pulled from the right-hand side of the box to the octanol on the left-side. 

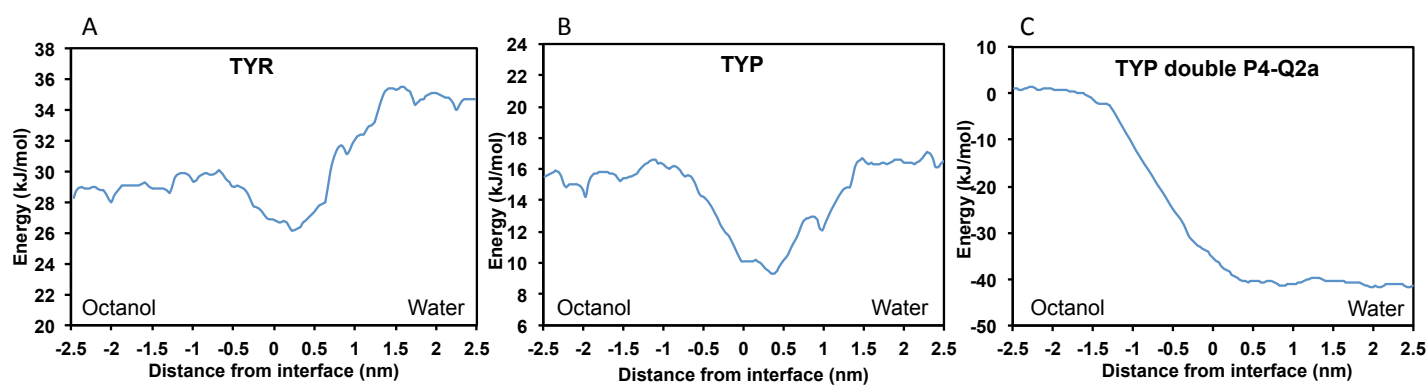

Figure S6. Free Energy landscapes when pulling from water to octanol phase using umbrella sampling for each amino acid: (A) Tyrosine; (B) Phosphorylated tyrosine; (C) Phosphorylated tyrosine using Q2a.

Table S1. Free energy difference and calculated $\log \mathrm{P}$ values for each amino acid

\begin{tabular}{cccc}
\hline & \multicolumn{1}{c}{ log $\mathbf{c}$} \\
\hline & $(\mathrm{kJ} / \mathrm{mol})$ & Calculated & Experimental \\
\hline TYR & -5.6 & 1 & $2.3^{5}$ \\
\hline TYP & -0.50 & 0 & \\
\hline TYP double P4-Q2a & 41 & -7 & \\
\hline
\end{tabular}

Although phosphorylated tyrosine presents a lower tendency to move to the octanol when in comparison to tyrosine (Figure S6B compared to Figure S6A), hydrophilicity is not completely achieved since the reverse migration to octanol is still favorable. The developers of Martini warn of the possible need to increase the solvation free energy for $\mathrm{Ca}^{2+}$ ions to achieve a realistic description of this ion. ${ }^{6}$ Since they also report on improved behaviour by increasing the hydration strength of phosphate moieties, ${ }^{6}$ we increased the Lennard-Jones well-depth for water-phosphate interactions (P4-Q2a). To achieve this, we created a new bead, called Q2a, and increased by a factor of two the $\mathrm{C}_{6}$ and $\mathrm{C}_{12}$ values for $\mathrm{P} 4-\mathrm{Q} 2 \mathrm{a}$ present in martini_v2.2.itp file, when in comparison with P4-Qa. Consequently, the migration from water to octanol was very unfavorable, with a $\log \mathrm{P}$ value of -7.3 . Thus, while the standard tyrosine parameterisation underestimates the hydrophobicity of tyrosine (calculated $\log \mathrm{P}=1$ vs. experimental $\log \mathrm{P}=2$; Table $\mathrm{S} 1$ ), the hydrophilicity of the phosphorylated tyrosine is overestimated (calculated $\log \mathrm{P}=-7$ vs. experimental $\log \mathrm{P}$ 
$=-2$; Table S1). While the difference between the calculated and experimental $\log \mathrm{P}$ values is relatively large, we believe that it is acceptable given the deviations seen across the parameterized amino acids within the Martini description $(\mathrm{MUE}(\log \mathrm{P})=$ 1.5; $\operatorname{MAXE}(\log \mathrm{P})=4, \operatorname{MINE}(\log \mathrm{P})=-3){ }^{1}$

Therefore, the modified LJ parameters were used for the KYpF simulations, where Q2a was used to represent the phosphate group. In fact, it was observed that the preference of these Q2a beads to be in contact with a water environment is the reason why no fibers are formed in the case of $\mathrm{KYpF}$. This was determined by running comparative simulations of the KYpF system using the initial parameterization of the Qa bead (with the standard P4-Qa interaction potential) with a -2 charge (TYP), which resulted in fiber formation (see Figure below), which is not consistent with the experimental results.

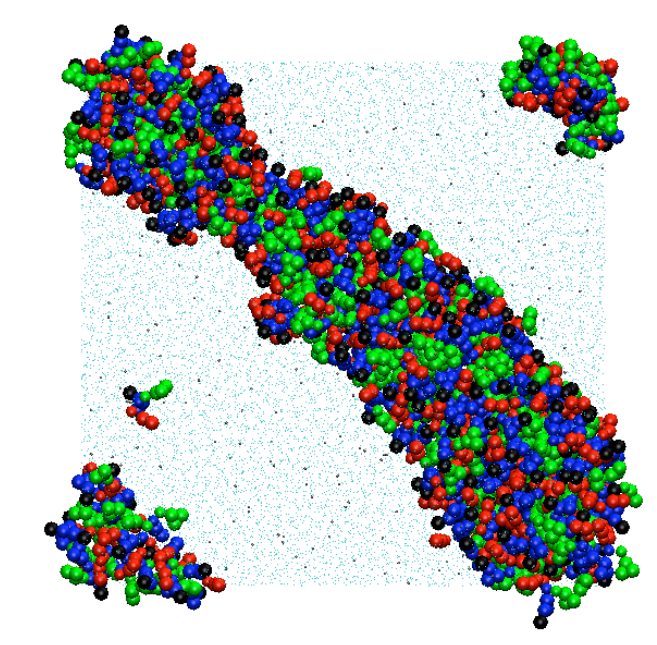

Figure S7. Snapshot after $10 \mu \mathrm{s}$ CG-MD simulation of KYpF when Qa bead is used, showing fiber formation.

The stronger non-bonded interactions between phosphate groups from tyrosine and water molecules are thus critical for the formation of aggregates, more than the repulsion effect caused by the charged groups, which was initially expected to be the governing interaction.

\section{Partition coefficient using experimental determination}

The shake-flask method was used to determine the partition coefficient experimentally. The emission of phosphorylated tyrosine samples of known concentrations in water and octanol was measured using the spectrofluorometer. 

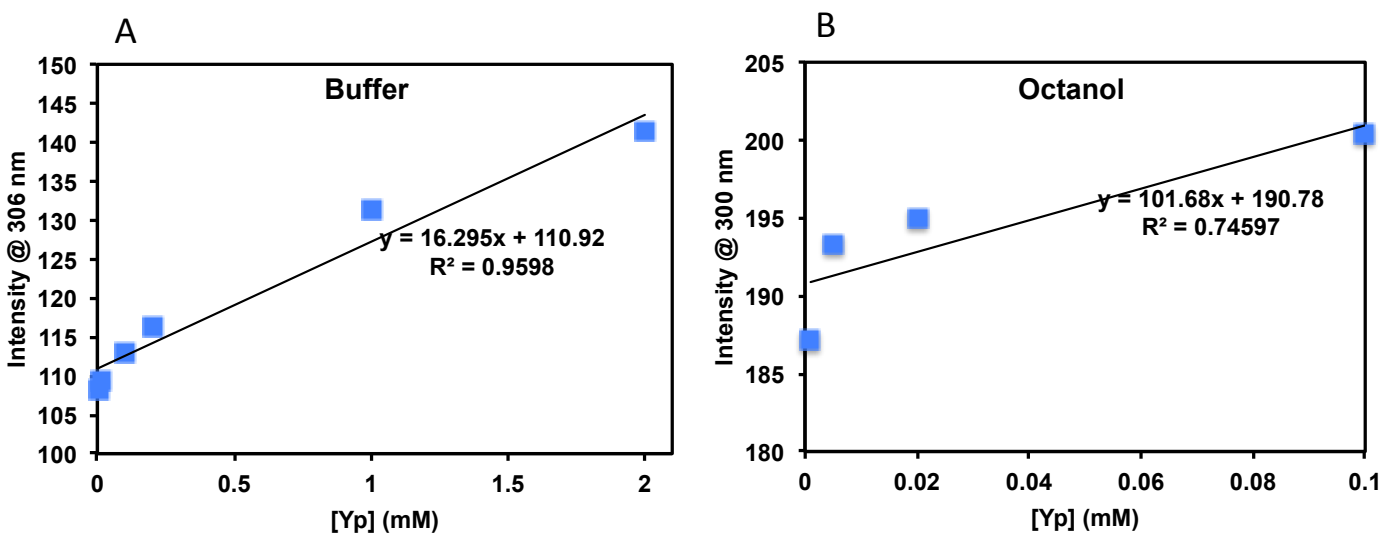

Figure S8. Calibration of the emission fluorescence intensity for phospho-tyrosine in different concentrations in (A) aqueous phosphate buffer and (B) 1-octanol.

To samples of $2 \mathrm{~mL}$ of phospho-tyrosine $(1 \mathrm{nM})$ in $\mathrm{pH} 80.1 \mathrm{M}$ phosphate buffer were added $2 \mathrm{~mL}$ of octanol and vigorously shaken for $30 \mathrm{sec}$. After leaving the samples to stand for $4 \mathrm{~h}$ at room temperature, $1 \mathrm{~mL}$ of each phase was taken to a cuvette and the fluorescence spectroscopy emission measured. Averaged results of 7 different samples were taken to determine the partition coefficient and $\log \mathrm{P}$ value.

Table S2. Experimental results for partition coefficient $\left(\mathrm{K}_{\mathrm{ow}}\right)$ and $\log \mathrm{P}$ determination of $\mathrm{Yp}$

\begin{tabular}{ccc}
\hline & Kow $_{\text {ow }}$ & logP \\
\hline $\mathbf{1}$ & 0.029 & -1.53 \\
$\mathbf{2}$ & 0.022 & -1.67 \\
$\mathbf{3}$ & 0.009 & -2.03 \\
$\mathbf{4}$ & 0.002 & -2.76 \\
$\mathbf{5}$ & 0.003 & -2.60 \\
$\mathbf{6}$ & 0.004 & -2.37 \\
$\mathbf{7}$ & 0.007 & -2.14 \\
\hline Average & 0.011 & -2.16 \\
St Dev & 0.010 & 0.454 \\
\hline
\end{tabular}




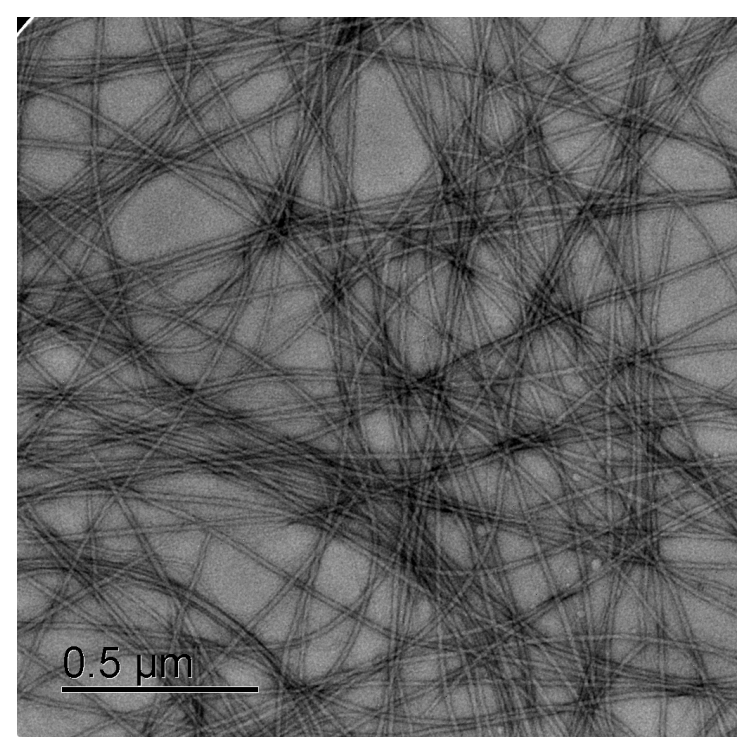

Figure S9. TEM image of non-enzymatically produced KYF hydrogel after $24 \mathrm{~h}$ of preparation. 

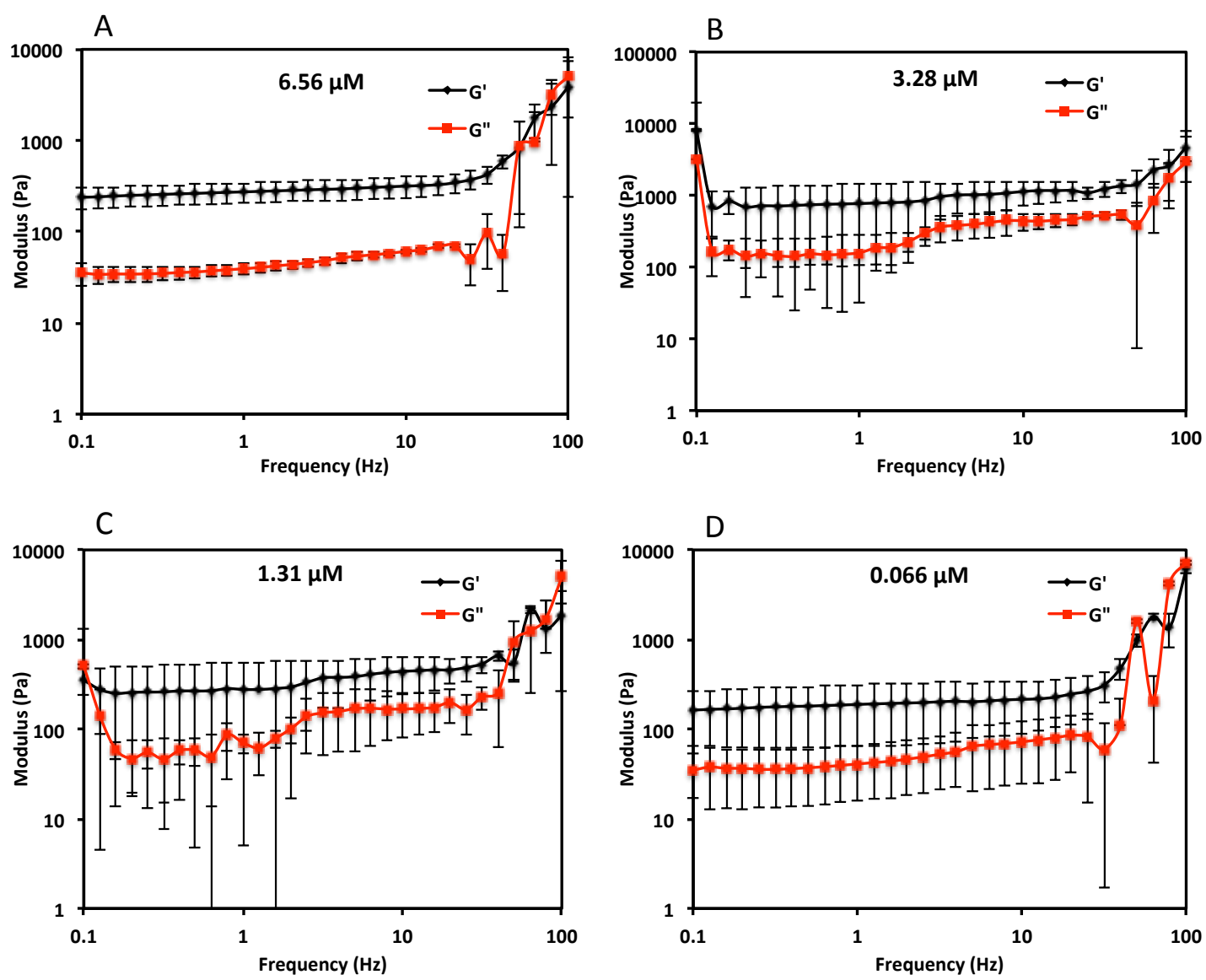

Figure S10. Frequency sweep measurements showing viscoelastic behaviour of the different produced hydrogels: (A) KYpF + 6.56 $\mu \mathrm{M}$ AP; (B) KYpF + 3.28 $\mu \mathrm{M} \mathrm{AP}$; (C) KYpF + 1.31 $\mu \mathrm{M} \mathrm{AP}$; (D) KYpF $+0.066 \mu \mathrm{M}$ AP. 


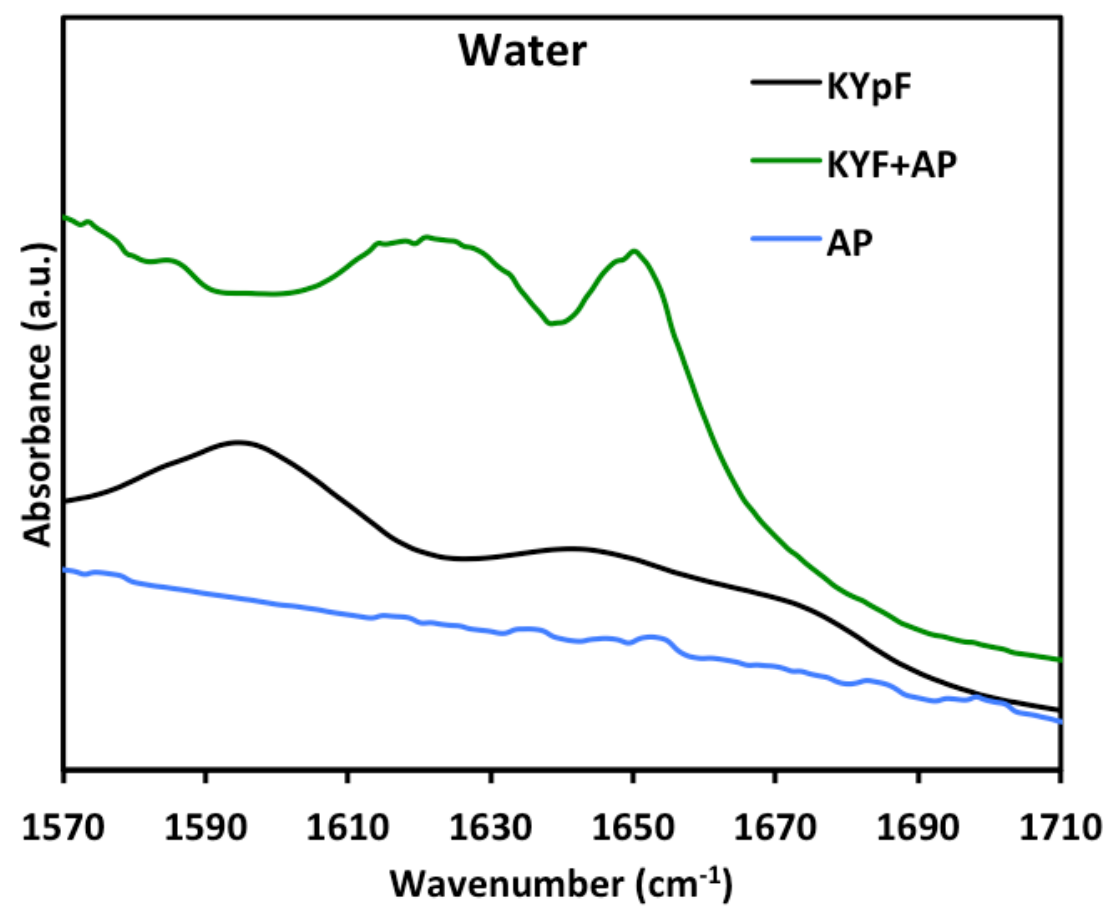

Figure S11. FTIR amide I spectra for the control of only alkaline phosphatase and of chemical KYF when added alkaline phosphatase. 


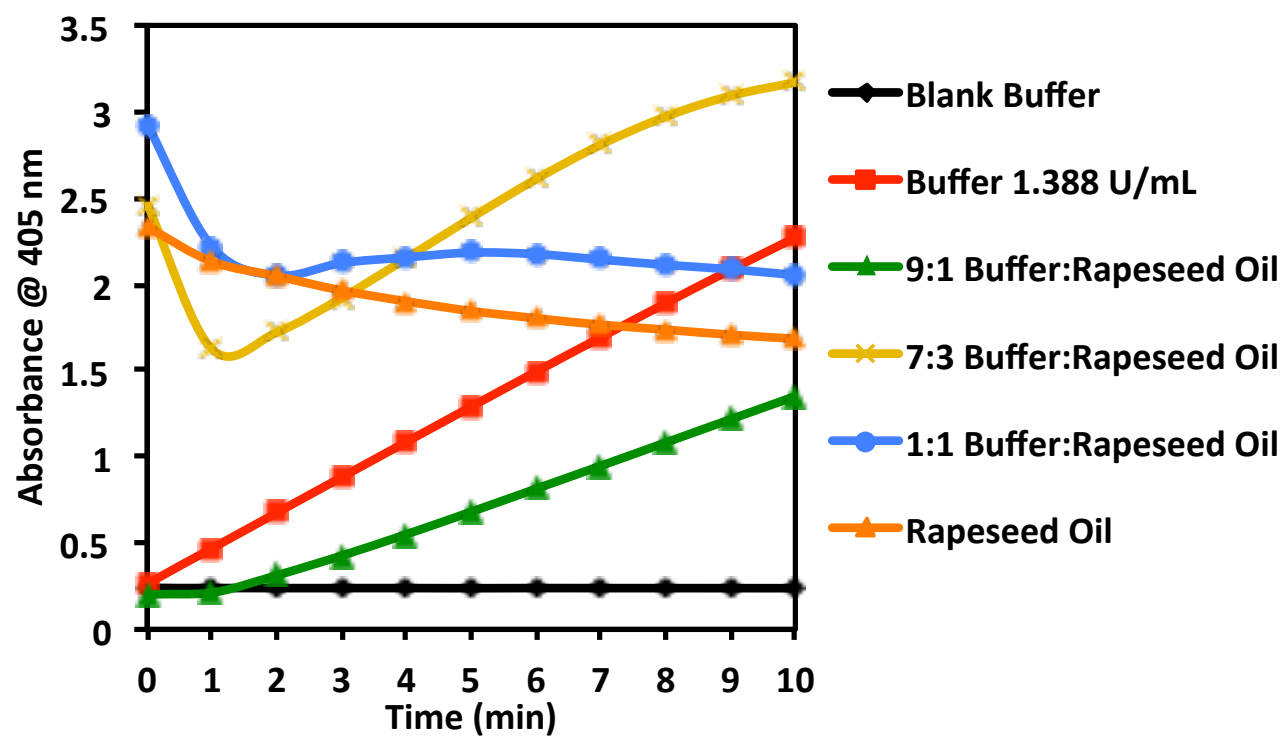

Figure S12. Enzyme activity in different (non-)aqueous systems, where the dephosphorylation reaction of 4-nitrophenyl phosphate (pNPP) is monitored by the UV-Vis absorbance at $405 \mathrm{~nm}$ through $10 \mathrm{~min}$. 
A

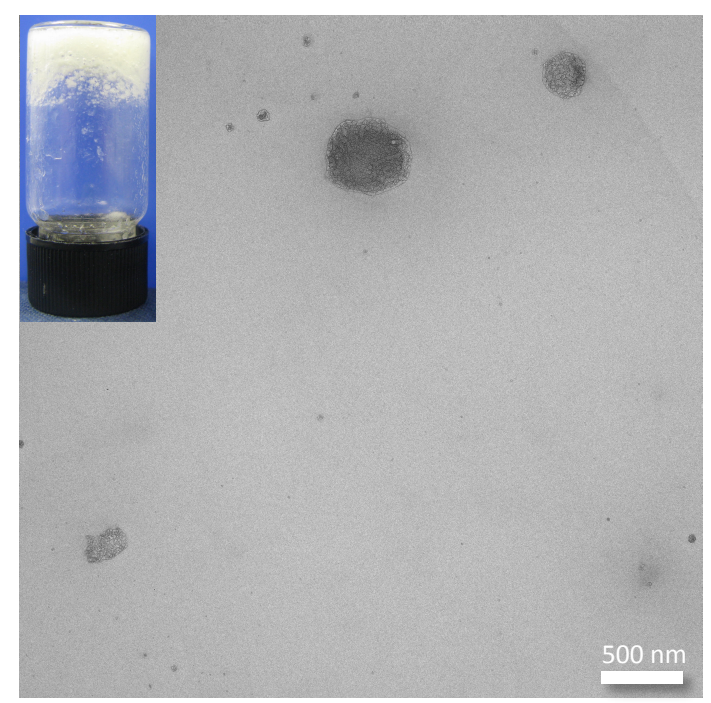

B

Figure S13. Photographs of macroscopic aspect and TEM images obtained after 24 hours of the 9:1 buffer:rapeseed oil samples: (A) KYpF added $1.31 \mu \mathrm{M}$ alkaline phosphatase; (B) $3.28 \mu \mathrm{M}$ AP. 


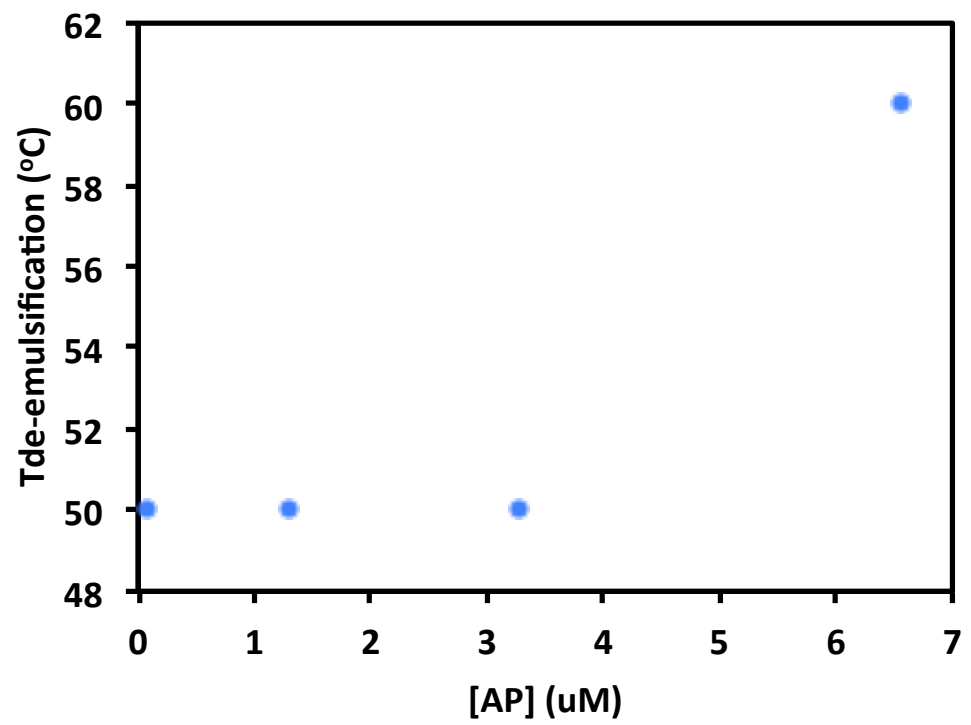

Figure S14. De-emulsification temperature for the emulsions where various concentrations of alkaline phosphatase are used. Based on macroscopic analysis of the emulsions when temperature is increased each $5{ }^{\circ} \mathrm{C}$ from 40 until $60^{\circ} \mathrm{C}$ and left at each temperature for $30 \mathrm{~min}$. 
A

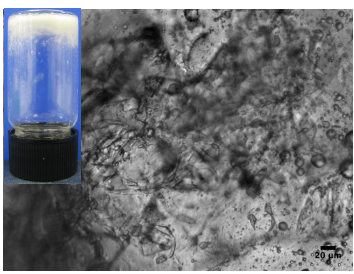

$\mathrm{E}$

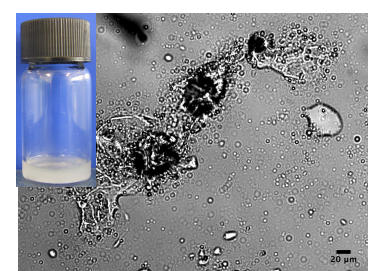

B

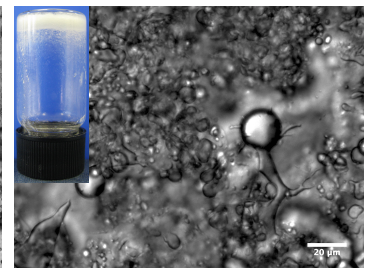

$\mathrm{F}$

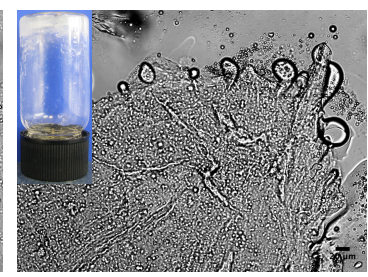

C

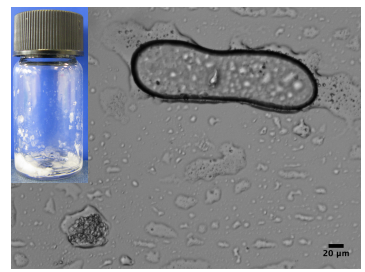

G

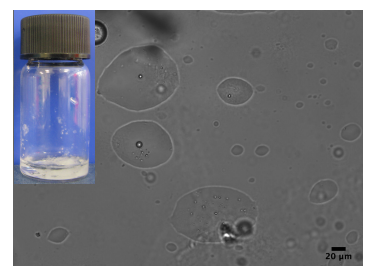

D

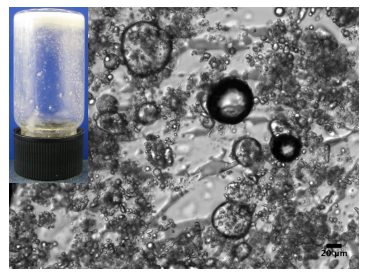

$\mathrm{H}$

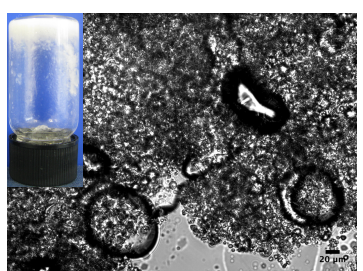

Figure S15. Photograph of the macroscopic aspect and light microscopy image of the oil-in-water emulsions when added $6.56 \mu \mathrm{M}$ alkaline phosphatase upon preparation (A-D): (A) After $1 \mathrm{~h}$; (B) After $24 \mathrm{~h}$; (C) After increasing temperature to $60^{\circ} \mathrm{C}$; (D) After cooling it down to room temperature overnight and homogenizing again; Photograph of the macroscopic aspect and light microscopy image of the oil-in-water emulsions when added $3.28 \mu \mathrm{M}$ alkaline phosphatase upon preparation (E-H): (E) After $1 \mathrm{~h}$; (F) After $24 \mathrm{~h}$; (G) After increasing temperature to $60^{\circ} \mathrm{C}$; (H) After cooling it down to room temperature and homogenizing again.

\section{References}

1. Monticelli, L.; Kandasamy, S. K.; Periole, X.; Larson, R. G.; Tieleman, D. P.; Marrink, S.-J., The MARTINI coarse-grained force field: extension to proteins. Journal of chemical theory and computation 2008, 4 (5), 819-834.

2. $\quad$ de Jong, D. H.; Singh, G.; Bennett, W. D.; Arnarez, C.; Wassenaar, T. A.; Schäfer, L. V.; Periole, X.; Tieleman, D. P.; Marrink, S. J., Improved parameters for the martini coarsegrained protein force field. Journal of Chemical Theory and Computation 2012, 9 (1), 687 697.

3. http://www.cgmartini.nl/index.php/downloads/tools/204-martinize.

4. Hub, J. S.; De Groot, B. L.; Van Der Spoel, D., g_wham A Free Weighted Histogram Analysis Implementation Including Robust Error and Autocorrelation Estimates. Journal of Chemical Theory and Computation 2010, 6 (12), 3713-3720.

5. Verschueren, K., Handbook of environmental data on organic chemicals. 1983.

6. Marrink, S. J.; Risselada, H. J.; Yefimov, S.; Tieleman, D. P.; De Vries, A. H., The MARTINI force field: coarse grained model for biomolecular simulations. The Journal of Physical Chemistry B 2007, 111 (27), 7812-7824. 